\title{
Recent Advances in Thermal Interface Materials
}

Yongcun $\mathrm{Zhou}^{1,2^{*}}$, Siqi $\mathrm{Wu}^{1}$, Yuheng Long ${ }^{3}$, Pengli Zhu ${ }^{4}$, Feixiang $\mathrm{Wu}^{5}$, Feng Liu ${ }^{1,6}$, Vignesh Murugadoss ${ }^{7,8}$, Williams Winchester ${ }^{9}$, Amit Nautiyal $^{9}$, Zhe Wang $^{9 *}$ and Zhanhu Guo ${ }^{8 *}$

In recent years, miniaturization and integration have become the development trends of electronic devices. With the power of electronic devices continuing to increase, the amount of heat generated is sharply increasing. Thermal interface material (TIM) can effectively improve heat transfer between two solid interfaces, and it plays an important role in the performance, service life and stability of electronic devices. In this case, higher requirements are put forward for thermal management, so much attention is also attached to the innovation and optimization of TIM. In this paper, recent research development of TIM is reviewed. Rheology-based modeling and design are discussed for the widely used polymeric TIMs. It is discussed for the effects of thermal conductive fillers on the properties of composites. Many studies have shown that some polymers filled with high thermal conductivity and low loss ceramics are well suitable for electronic packaging for device encapsulation. Until now, extensive attentions have been paid to the preparation of polymeric composites with high thermal conductivity for the application in electronic packaging. Finally, the problems are also discussed and the research directions of TIM in the future are prospected.

Keywords: Thermal interface material (TIM); Thermal conductivity; Thermal management; Modeling

Received 15 February 2020, Accepted 5 March 2020

DOI: $10.30919 / \mathrm{esmm} 5 \mathrm{f} 717$

\section{Introduction}

\subsection{What is Thermal Interface material?}

In recent years, miniaturization and integration have become the development trends of electronic devices. With continuingly increasing power of electronic devices, the amount of heat generated is sharply increasing. ${ }^{1-5}$ Owing to roughness in morphology, just a small fraction of the apparent surface area will have an actual contact when two solid surfaces are joined. ${ }^{6-10}$ The rest of the area will be separated by an air-filled gap, and since the thermal conductivity of air $(0.026 \mathrm{~W} / \mathrm{mK})$ is about four orders of magnitude lower than that of metals, heat transfer across the interface through air is negligible. The bulk of the heat flux will go through the actual contacting points, which presents a severe thermal bottleneck even for substrates with avery low roughness. This exhibits itself as a temperature drop across the interface as seen in Fig. 1. As a result, TIM is placed between two mating surfaces to increase the thermal conductance over the interface.

The TIM is typically made of a material that is compliant and can fill out the voids in between the two surfaces, thereby increasing the effective contact area. An ideal TIM would only fill the existing voids in the interface with a thermally conductive material. In a realistic application, the thickness of the TIM will create a gap between the two mating surfaces, but

\footnotetext{
${ }^{1}$ School of Material Science and Engineering, Northwestern Polytechnical University, Xi' an 710072, China

${ }^{2}$ Yangtze River Delta Research Institute of Northwestern Polytechnical University, Taicang 215400, China

${ }^{3}$ Queen Mary University of London Engineering School, Northwestern Polytechnical University, Xi'an 710072, China

${ }^{4}$ Shenzhen Institute of Advanced Electronic Materials, Shenzhen Fundamental Research Institutions, Shenzhen Institutes of Advanced Technology, Chinese Academy of Sciences, Shenzhen 518055, China

${ }^{5}$ School of Metallurgy and Environment, Central South University, Changsha 410083, China

${ }^{6}$ Analytical \& Testing Center, Northwestern Polytechnical University, Xi' an 710072, China

${ }^{7}$ Electro-Materials Research Laboratory, Centre for Nanoscience and Technology, Pondicherry University, Puducherry 605014, India

${ }^{8}$ Integrated Composites Laboratory (ICL), Department of Chemical and Biomolecular Engineering, University of Tennessee, Knoxville, TN 37996, USA

${ }^{9}$ Chemistry Department, Xavier University of Louisiana, New Orleans 70125, USA

*E-mail: yczhou@nwpu.edu.cn(Y.Zhou); zwang@xula.edu(Z.Wang); zguo10@utk.edu(Z.Guo); nanomaterials2000@gmail.com
} 


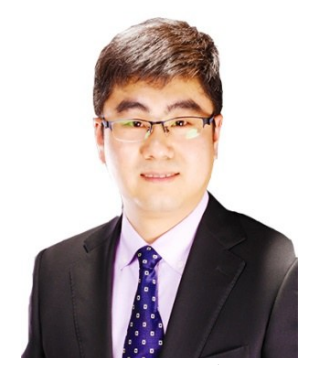

Yongcun Zhou

Dr. Yongcun Zhou received his Ph.D. degree in electronic science and technology in Xi'an Jiaotong University (XJTU), China in 2014. He researched at Georgia Institute of Technology (Georgia Tech) from 2012 to 2014 as a visiting scholar. Currently, he is an Associate Professorat the School of Materials Science and Engineering, Northwestern Polytechnical University (NPU) in China. His current research interests lie in the fields of thermally conductive polymeric materials, electronic packaging, ablation-resistance polymeric composites, phase change material and nano-functional material syntheses and characterizations.

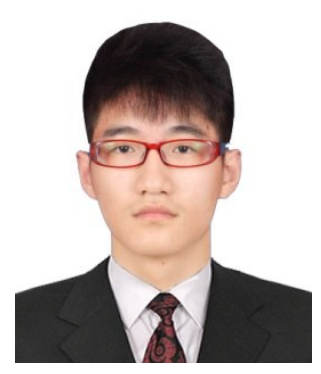

Siqi $\mathrm{Wu}$

Mr. Siqi Wu, will receive his Postgraduate degree at Northwestern Polytechnical University (NPU), China. Currently, he is an undergraduate with major of Materials and Chemical Engineering at the School of Materials Science and Engineering, NPU. His research interest mainly focuses on the preparation and application of multifunctional polymer nanocomposites and conducting polymer nanocomposites.

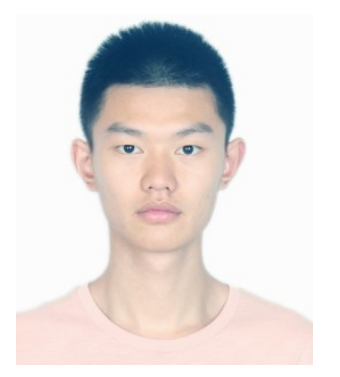

Yuheng Long
Mr. Yuheng Long, will receive his Bachelor's degree at Northwestern Polytechnical University (NPU), China. Currently, he is an undergraduate with major of Materials Science and Engineering at the Queen Mary Engineering School, NPU. His research interest mainly focuses on the preparation and application of multifunctional polymer nanocomposites and conducting polymer nanocomposites.

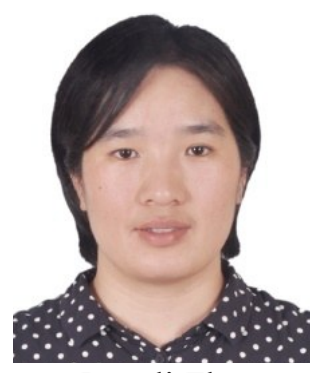

Pengli Zhu

Dr. Pengli Zhu, a professor in Shenzhen Institutes of Advanced Technology, Chinese Academy of Sciences (SIAT-CAS). She received the Ph. D. degree from the Chinese Academy of Sciences, Beijing, China, in 2010. Her research interests include the nanomaterials, functional nanocomposites and their corresponding applications in the flexible electronics, and electronic packaging.

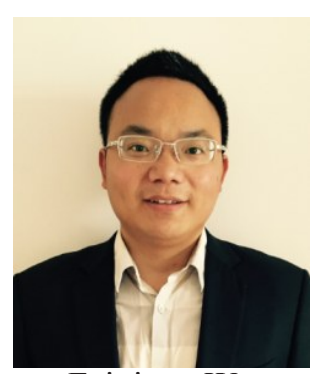

Feixiang Wu
Dr. Feixiang Wu, a professor of the School of Metallurgy and Environment at the Central South University (CSU). He received his Ph.D. in Metallurgical Physics and Chemistry in 2014 at CSU. From 2012 to 2014, he was a visiting scholar in Prof. Yushin's laboratory in Materials Science at the Georgia Institute of Technology (GT). After graduation, he worked as a research associate in Yushin group at GT (2015-2016). From 2016 to 2019, he worked as a Humboldt Fellow in Maier group at the Max Planck Institute for Solid-State Research. His research interests focus on materials and electrolytes for rechargeable batteries. 


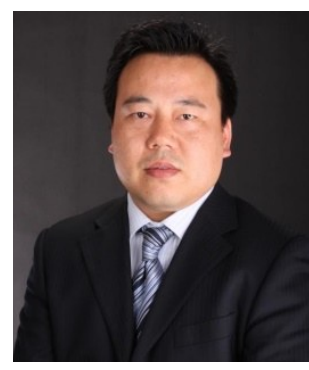

Feng Liu

Dr. Feng Liu, a full professor and leader of Rapid Solidification and Metastable Materials Research in State Key Laboratory of Solidification Processing at the Northwestern Polytechnical University (NPU). He earned his Ph.D. degree from NPU in 2001. After his doctoral study, he was awarded more than there-year postdoctoral and Humboldt research cooperation in Max Planck Institute for Metals Research. His research interests lie in the fields of non-equilibrium solidification theory and technology, unifying theories research between non-equilibrium solidification and solid transformation, solid-state phase transformation kinetics, preparation and stability study of amorphous and metastable nanomaterials and preparation of high strength aluminum magnesium alloys.

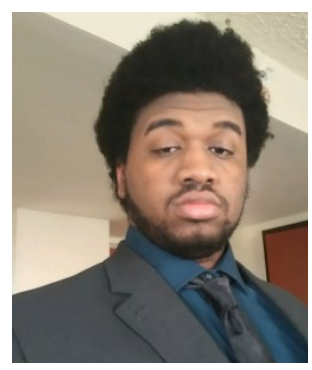

William Winchester
Mr. William Winchester, an undergraduate student at Xavier University of Louisiana. He first enrolled at Delgado community college where he obtained his Associates in physical sciences. He then transferred to Xavier University of Louisiana where he is a senior ACS chemistry major with minors in physics and math. He is currently an undergraduate researcher under NIH BUILD where he has been for 2 years working under Dr. Zhe Wang. Williams' main areas of interest are electrochemistry and inorganic chemistry with plans to obtain a PhD in chemistry after completing his bachelor's degree.
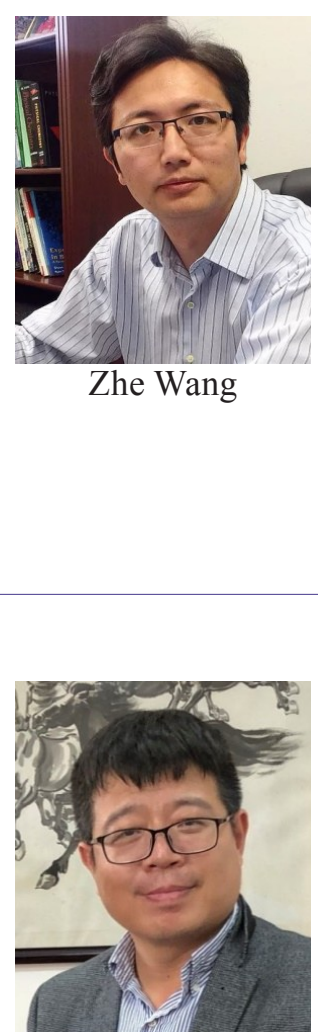

Zhanhu Guo
Dr. Zhe Wang, an assistant professor at Xavier University of Louisiana. He earned a B.S. in chemistry in 2001, and received his Ph.D. in analytical chemistry in 2007 at the Lanzhou University. He worked on the nano-electrochemistry for small molecule conversion. From 2007-2009, Dr. Wang served as a postdoctoral fellow at University of California Los Angeles, where he worked on the multifunctional nanomaterial for advance engineering and electrochemistry project. Before he join Xavier University of Louisiana in 2014, Dr. Wang held a research associate position at Oakland University from 2009-2014, to study ionic liquid electrochemistry and bioelectrochemistry for sensor and biosensor array system. Dr. Wang has published more than 50 papers in peer-reviewed journals and two US patents. Currently, he is serving as the area chair of composite division in AlChE.

Prof. Zhanhu Guo, an associate professor in the Department of Chemical and Biomolecular Engineering, University of Tennessee, Knoxville, USA. He obtained a $\mathrm{PhD}$ degree in Chemical Engineering from Louisiana State University (2005), and received three-year (2005-2008) postdoctoral training from the Mechanical and Aerospace Engineering Department at the University of California Los Angeles. Dr Guo chaired the Composite Division of the American Institute of Chemical Engineers (AIChE, 2010-2011). Dr. Guo is the director of the Integrated Composites Laboratory. His current research focuses on multifunctional nanocomposites for energy, electronic and environmental applications. 
the improvement in thermal conductivity of the TIM compared to the ambient fluid still gives a big improvement on the interfacial heat transfer.
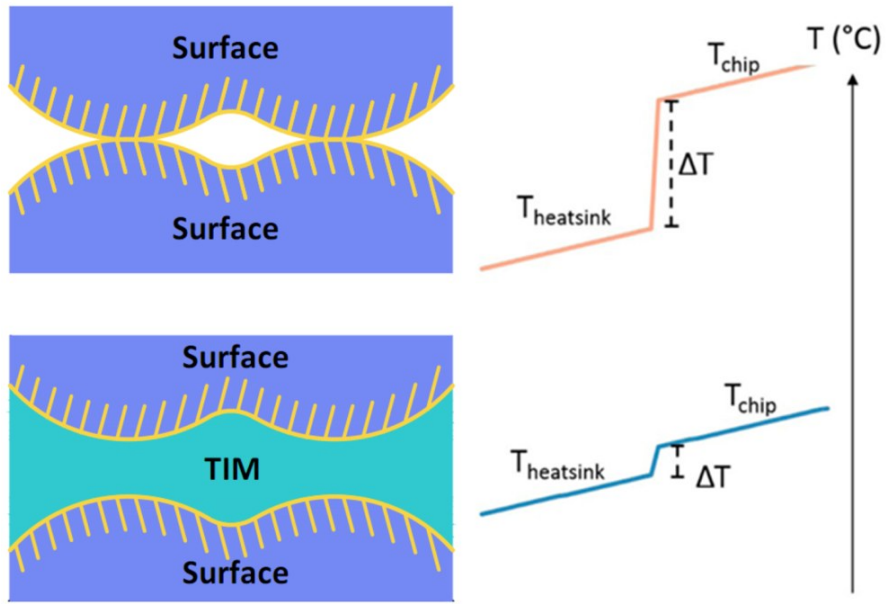

Fig. 1 Schematic representation of working principle of a TIM. An interface lacking a TIM will have a very concentrated heat flux, causing a large temperature drop at the interface. A TIM fills out the voids and reduces the temperature drop over the interface.



Fig. 2 Schematic illustration of a typical ball grid array (BGA) electronics package with two TIMs. The heat is conducted through the backside of a BGA chip. There are TIMs between chip and IHS and between IHS and heat sink. The different TIM applications are called TIM1 and TIM2, respectively.

In an electronics package, TIMs are usually employed at all interfaces between two solid materials. Typically these interfaces occur between heat-generating die and integrated heat spreader (IHS) as well as between the IHS and a heat sink. These two TIM applications are called TIM1 and TIM2, respectively, and are illustrated in Fig. 2. There are also packages with a single TIM connecting a die directly with a heat sink and packages with more than two TIM instances between chip and heat sink. ${ }^{11}$ The thermal performance of a TIM is generally evaluated according to its thermal interface resistance $\left(R_{\mathrm{TIM}}\right)$, which is a measure on how difficult it is for heat to dissipate over the interface. It is related to the temperature drop $(\triangle T)$ over the interface according to Fourier's law as $\triangle T=R_{\text {TIM }} \mathrm{Q}$, where $\mathrm{Q}$ is the heat flux. Minimizing $R_{\text {TIM }}$ is a general goal of TIM's development. The thermal interface resistance can be divided into resistive components, for a TIM typically:

$$
R_{T I M}=\frac{B L T}{\lambda_{T I M}}+R_{c 1}+R_{c 2}
$$

where $R_{T I M}$ is the total thermal interface resistance, $R_{c 1}$ and $R_{c 2}$ are the contact resistances at the interface between the TIM and the two substrates, $\lambda_{\text {TIM }}$ the thermal conductivity of the TIM and BLT is the bond line thickness, i.e. the thickness of the TIM. Depending on the type of TIM and application, the different terms of the equation will have more or less impact on the overall performance, and when choosing or designing a TIM, it is important to identify which parameters to optimise.

$R_{c}$-Between substrate and TIM, there is a contact resistance depending on the thermal contact. This contact resistance depends on how well the TIM conforms to the substrate and fills out voids. It is affected by the compliancy of the TIM as well as how well it wets to the substrates, and can be very dependent on applied pressure for some TIMs. There is also a thermal boundary resistance between two different materials, even if atomically smooth due to phonon or electron scattering at the interface. This effect is called Kapitza resistance. ${ }^{12}$ The bond line thickness (BLT) of the TIM is a measure of how separated the two surfaces are i.e. how thick the TIM is. As the TIM typically still has a significantly lower thermal conductivity than either of the substrates, it is desirable to minimise the BLT. In addition, a lower BLT means less material used, and thus usually a lower cost as well. Ideally the TIM fills out only the voids in the original interface. However, in practice a very thin bond line can result in voiding due to uneven TIM coverage as well as reliability issues during thermal cycling due to mismatch in coefficient of thermal expansion (CTE). For TIMs in liquid form, the BLT is influenced not only by the amount of material but also by the viscosity of the material and clamping pressure. In addition, for TIM loaded with solid filler particles, the size of the fillers can introduce a limit on how thin BLT is possible. For a TIM applied as a pad, the BLT is limited by handling and mechanical requirements. The thermal conductivity $(\lambda)$ of the TIM is the measure on how well the material conducts heat within itself. The importance of a high thermal conductivity is proportional to the BLT i.e. for very low bond line thickness, the contact resistance dominates over the resistance due to thermal conductivity, but for thick TIMs the thermal conductivity becomes a critical parameter.

In recent years, there has been a great drive in the industry in reducing $R_{T I M}$. The heat flux from the chip is non-uniform, ${ }^{13,14}$ because both the core and cache are on the same die. 
Majority of power is dissipated from the core, i.e., from a much smaller area of the chip. Even within the core, heat flux $(q)$ is non-uniform. Mahajan et al. ${ }^{13}$ discussed the issue of the nonuniform heat fluxes from the die and indicated that cooling solutions were not only needed to maintain the average chip temperature below a design point, it was also important to maintain the temperature of the hottest spot below a certain design point. Therefore, the thermal problem near the chip is very severe. The total thermal resistance for non-uniform heating can be written as: ${ }^{15}$

$$
\psi_{j-a}=\mathrm{DF} \times R_{j c}+\psi_{c s}+\psi_{s a}
$$

where $\psi_{j-a}$ is the junction to ambient thermal resistance, $R_{j c}$ the junction to case thermal impedance for an uniformly heated die, $\psi_{c s}$ is the case to sink resistance, and $\psi_{s a}$ is the sink to ambient thermal resistance. DF in Eq. (2) is called "Density Factor" that accounts for the non-uniformity of $q$ and the die size. ${ }^{15}$ The unit of DF is $\mathrm{cm}^{-2}$. For a $1 \mathrm{~cm}^{2}$ uniformly heated chip, the DF is 1 . DF is typically larger than 1 for most microprocessors due to high non-uniformity of $\mathrm{q}$ and small die sizes, but theoretically DF can approach zero for very large die. According to Eq. (2), a reduction in both $R_{j c}$ and DF leads to a reduction in $\psi_{j-a}$. Note that the reduction of $R_{j c}$ leads to a greater reduction in $\psi_{j-a}$ if DF is larger than 1 . Since $R_{j c}$ is primarily due to TIM thermal resistance, this has lead to a great drive in the electronics cooling industry to develop better TIMs. An ideal TIM consists of a material combining low bond line thickness with a high thermal conductivity and a low thermal contact resistance. However, aside from the thermal interface resistance, there are a number of other parameters to be considered when choosing or designing a TIM. Whether the TIM is electrically insulating or not can be relevant, as other specifications are related to the mechanical properties of the TIM, which affect the handling capability as well as reliability issues. A TIM can be in either liquid or solid form, and not necessary be the same during handling as during operation. TIMs that are liquid during handling can lead to a somewhat messy process and uncertain BLT, but are generally able to infiltrate voids well if the viscosity is low enough, while applying as a pad is a much more simple process but might not be able to conform to the substrates as well. The importance of the conformability parameter depends on the substrate roughness and flatness.

During operation, liquid TIMs may be susceptible to effects that negatively affect the reliability. During thermal cycling, the package will undergo mechanical deformations, which tends to spread out the TIM further, eventually pumping out material from between the surfaces. This pump-out effect can be a significant problem for liquid TIMs. Another aspect to consider is whether the TIM can act as an adhesive or if it requires external pressure. TIMs that are liquid during operation will need an applied pressure to hold the system together, also depending on the viscosity of the TIM. TIMs that are solid during both handling and operation will generally require a significant pressure to make the TIM conform to the substrates. On the other hand, there are TIMs that also function as adhesives which will bond the two substrates together and do not require any external pressure during operation, although it can cause delamination issues which can be a reliability concern.

\section{Recent Progress in Modeling of TIM}

In order to accurately model the physics of TIM performance, we need to understand: (1) $\lambda_{T T M}$, (2) BLT, and (3) $R_{\mathrm{c}}$ according to Eq. (1). Eq. (1) shows that $R_{\text {TIM }}$ can be reduced by reducing the BLT, increasing the thermal conductivity $\lambda_{T T M}$, and reducing the contact resistances $R_{c 1}$ and $R_{c 2}$. Table 1 summarizes the characteristics of various TIMs ${ }^{15,16}$ and their advantages and disadvantages. Since most TIMs are loaded with solid particle fillers, the physics to describe TIM thermal performance becomes complicated. Prasher ${ }^{17}$ first attempted to separate the bulk resistance $\left(R_{\text {bulk }}\right)$ and $R_{\mathrm{c}}$ by proposing a physical model, Prasher and co-workers have introduced various models for BLT, $\lambda_{\text {TIM }}$, and $R_{\mathrm{c}}$ in a series of papers. ${ }^{17-21}$ They mainly focus on grease, gel, and phase change materials (PCM) since these TIMs are most widely used as compared to elastomers. ${ }^{22}$ In the following sections, modeling of $\lambda_{\text {TIM }}$, BLT, and $R_{\mathrm{c}}$ for different types of TIMs is illustrated sequentially.

\subsection{Model to Predict Thermal Conductivity $\left(\lambda_{T I M}\right)$}

Since most polymeric TIMs are typically filled with highly thermal conductive particles to increase $\lambda_{T T M}$, these TIMs can be treated as composites. In general,thermal conductivity of any composite can be written as: ${ }^{22}$

$$
\lambda_{c}=f\left(\lambda_{m}, \lambda_{p}, R_{b}, \phi\right)
$$

where $\lambda_{m}$ is the thermal conductivity of the matrix, $\lambda_{p}$ is the thermal conductivity of the particles, $R_{b}$ the interface resistance between the particle and the matrix, and $\phi$ is the volume fraction of the particles. Many literatures can be found for modeling thermal conductivity of composites $\left(\lambda_{c}\right)$. Prasher ${ }^{22}$ has extensively discussed the merits and demerits of various models.

Table 2 lists various models to predict $\lambda_{c}$. Prasher ${ }^{19,22}$ found that Bruggeman asymmetric model (BAM) matches the experimental data of various polymeric TIM. BAM is very successful in modeling $\lambda_{T I M}$. BAM matches the data by assuming $\alpha$ (Biot number) of 0.1 . Assuming $\lambda_{m}$ of $0.2 \mathrm{~W} / \mathrm{mK}$ and particle diameter $(d)$ of $10 \mu \mathrm{m}$ (typical in commercial TIMs), $\alpha=0.1$ gives $R_{\mathrm{b}}=5 \times 10^{6} \mathrm{Km}^{2} \mathrm{~W}^{-1} . R_{\mathrm{b}}$ at the interface between the particle and the matrix could arise due to phonon acoustic mismatch or incomplete wetting of the interface by the polymer. $R_{\mathrm{b}}$ due to phonon acoustic mismatch is of the order of $10^{-8} \mathrm{~K} \mathrm{~m}^{2} \mathrm{~W}^{-1}$ at room temperatures, resulting in $\alpha$ of 0.0002 
Table 1 Summary of characteristics of some typical TIMs.

\begin{tabular}{|c|c|c|c|c|}
\hline TIM type & $\begin{array}{l}R_{\mathrm{TIM}} \text { of fresh } \\
\text { samples } \\
\left({ }^{\circ} \mathrm{C} \mathrm{cm}^{2} \mathrm{~W}^{-1}\right)^{23}\end{array}$ & $\begin{array}{l}\text { General } \\
\text { characteristics }\end{array}$ & Advantages & Disadvantages \\
\hline Greases & 0.1 & $\begin{array}{l}\text { Typically silicone- } \\
\text { based matrix loaded } \\
\text { with particles to } \\
\text { enhance thermal } \\
\text { conductivity }\end{array}$ & $\begin{array}{l}\cdot \text { High bulk thermal conductivity } \\
\cdot \text { Thin BLT with minimal attach } \\
\text { pressure } \\
\cdot \text { Low viscosity enables matrix } \\
\text { material to easily fill surface } \\
\text { crevices } \\
\cdot \text { No curing required } \\
\cdot \text { TIM elamination is not a concern }\end{array}$ & $\begin{array}{l}\text { - Susceptible to grease pump-out } \\
\text { and phase separation } \\
\text { - Considered messy in a } \\
\text { manufacturing environment due } \\
\text { to a tendency to migrate }\end{array}$ \\
\hline PCM & 0.1 & $\begin{array}{l}\text { Polyolefin, epoxy, } \\
\text { low molecular } \\
\text { weight polyesters, } \\
\text { acrylics typically } \\
\text { with BN or } \\
\mathrm{Al}_{2} \mathrm{O}_{3} \text { fillers }\end{array}$ & $\begin{array}{l}\text { - Higher viscosity leads to increased } \\
\text { stability and hence less susceptible } \\
\text { to pump-out } \\
\text { - Easier application and handling } \\
\text { than greases } \\
\text { - No cure required } \\
\text { - Delamination is not a concern }\end{array}$ & $\begin{array}{l}\text { - Lower thermal conductivity than } \\
\text { greases } \\
\text { - Surface resistance can be greater } \\
\text { than greases. Can be reduced by } \\
\text { thermal pre-treatment } \\
\text { - Requires attach } \\
\text { pressure to increase thermal } \\
\text { effectiveness and thus could lead } \\
\text { to increased mechanical stresses }\end{array}$ \\
\hline Gels & 0.08 & $\begin{array}{l}\mathrm{Al}, \mathrm{Al}_{2} \mathrm{O}_{3}, \mathrm{Ag} \\
\text { particles in silicone, } \\
\text { olefin matrices that } \\
\text { require curing }\end{array}$ & $\begin{array}{l}\text { - Conforms to surface irregularity } \\
\text { before cure } \\
\cdot \text { No pump-out or migration concerns }\end{array}$ & $\begin{array}{l}\text { - Cure process needed } \\
\text { - Lower thermal } \\
\text { conductivity than } \\
\text { grease } \\
\text { - Lower adhesion than adhesives; } \\
\text { delamination can be a concern }\end{array}$ \\
\hline Adhesives & $\begin{array}{l}\text { Data not } \\
\text { available }\end{array}$ & $\begin{array}{l}\text { Typically Ag } \\
\text { particles in a cured } \\
\text { epoxy matrix }\end{array}$ & $\begin{array}{l}\cdot \text { Conforms to surface irregularity } \\
\text { before cure } \\
\cdot \text { No pump-out } \\
\cdot \text { No migration }\end{array}$ & $\begin{array}{l}\text { - Cure process needed } \\
\cdot \text { Delamination post reliability } \\
\text { testing is a concern } \\
\text { - Since cured epoxies have } \\
\text { modulus, CTE mismatch induced } \\
\text { stress is a concern }\end{array}$ \\
\hline
\end{tabular}

$P C M$-phase change material

Table 2 Models to predict the thermal conductivity of particle-laden TIMs. ${ }^{19-22}$

\begin{tabular}{|c|c|c|}
\hline Name of themodel & Formula & Remarks \\
\hline $\begin{array}{l}\text { Maxwell-Garnett with } \\
R_{\mathrm{b}}\end{array}$ & $\begin{array}{l}\frac{\lambda_{c}}{\lambda_{m}}=\frac{\left[\lambda_{p}(1+2 \alpha)+2 \lambda_{m}\right]+2 \phi\left[\lambda_{p}(1-\alpha)-\lambda_{m}\right]}{\left[\lambda_{p}(1+2 \alpha)+2 \lambda_{m}\right]-\phi\left[\lambda_{p}(1-\alpha)-\lambda_{m}\right]} \\
\alpha=\frac{2 R_{b} \lambda_{m}}{d} \\
\frac{\lambda_{c}}{\lambda_{m}}=\frac{(1+2 \alpha)+2 \phi(1-\alpha)}{(1+2 \alpha)-\phi(1-\alpha)} \text { for } \lambda_{p} \gg \lambda_{m}\end{array}$ & $\begin{array}{l}\text { Spherical particles } \\
\text { Typicallyvalid for } \phi<0.4\end{array}$ \\
\hline $\begin{array}{l}\text { Bruggemansymmetric } \\
\text { model }\end{array}$ & $\begin{array}{l}(1-\phi) \frac{\lambda_{m}-\lambda_{c}}{\lambda_{m}+2 \lambda_{c}}+\phi \frac{\lambda_{p}-\lambda_{c}}{\lambda_{p}+2 \lambda_{c}}=0 \\
\left(R_{\mathrm{b}} \text { not included }\right)\end{array}$ & $\begin{array}{l}\text { Spherical particles } \\
\text { Typically } \\
\text { good at higher } \phi\end{array}$ \\
\hline $\begin{array}{l}\text { Bruggeman } \\
\text { asymmetric model }\end{array}$ & $\begin{array}{l}(1-\phi)^{3}=\left(\frac{\lambda_{m}}{\lambda_{c}}\right)^{(1+2 \alpha) /(1-\alpha)} \times\left\{\frac{\lambda_{c}-\lambda_{p}(1-\alpha)}{\lambda_{m}-\lambda_{p}(1-\alpha)}\right\}^{3 /(1-\alpha)} \\
\frac{\lambda_{c}}{\lambda_{m}}=\frac{1}{(1-\phi)^{3(1-\alpha) /(1+2 \alpha)}} \text { for } \lambda_{p} \gg \lambda_{m}\end{array}$ & Spherical particle \\
\hline
\end{tabular}

$\lambda_{m}=$ thermal conductivity of matrix, $\lambda_{p}=$ thermal conductivity of particles, $R_{\mathrm{b}}=$ interface resistance between particles and the matrix, $\phi=$ volume fraction of the particles. 
for the case with $d$ of $10 \mu \mathrm{m}$ and $\lambda_{m}$ of $0.2 \mathrm{~W} / \mathrm{mK}$. Prasher $e t$ al. also showed that phonon acoustic mismatch at room temperature is negligible when compared to incomplete particle wetting; however, phonon acoustic mismatch Table 1.

\subsection{Rheological Model to Predict TIM Bondline Thickness (BLT)}

Prasher et al. ${ }^{19}$ measured the viscosity of various silicone-based TIMs and indicated that these TIMs behave like HerschelBulkley (H-B) fluid. The viscosity $(\eta)$ for H-B fluid is given by

$$
\eta=\frac{\tau_{y}}{\dot{\gamma}}+K(\dot{\gamma})^{n-1}
$$

where $\tau_{y}$ is the yield stress of the polymer, $\dot{\gamma}$ is the strain rate, $K$ the consistency index, and $n$ is an empirical constant. Prasher et al. ${ }^{19}$ further showed that steady state BLT depends only on $\tau_{y}$. By applying law of conservation of momentum and mass, the BLT by using Eq. (5) can be expressed by

$$
\mathrm{BLT}=\frac{2}{3} r\left(\frac{\tau_{y}}{P}\right)
$$

where $r$ is the radius of the substrate and $P$ the applied pressure. However, Prasher et al. ${ }^{19}$ found that Eq. (5) underpredicted the actual TIM BLT by a huge margin. Thus, they decided to introduce an empirical model

$$
h_{L}=\mathrm{C}\left(\frac{\tau_{y}}{P}\right)^{m}
$$

where $C$ and $m$ are empirical constants. They found $m$ is 0.166 and $C$ is $0.31 \times 10^{-4}$. Subsequently, Prasher ${ }^{20}$ offered an explanation to Eq. (6) by applying finite size scaling argument to a percolating system of particles. A heterogeneous system can be macroscopically treated as homogenous only if the thickness (BLT in this case) is much larger than the diameter of the particles. At high pressures, the BLT of TIMs typically ranges from 20 to $50 \mu \mathrm{m}$. If theparticle diameter is of the order of $10 \mu \mathrm{m}$, then the TIM cannot be treated a macroscopically homogeneous system. Prasher ${ }^{20}$ used the finite size scaling of elasticity modulus ${ }^{24}$ for a thin percolating system as a clue to scale $\tau_{y}$ of the TIM. Prasher ${ }^{20}$ also considered the fact that if BLT $\gg d$ (at low pressures) then any BLT model should reduce to Eq. (5). Based on these arguments, Prasher's model (Called scaling-bulk (S-B) model) is given as

$$
\mathrm{BLT}=\frac{2}{3} r\left\lfloor c\left(\frac{d}{B L T}\right)^{4.3}+1\right\rfloor\left(\frac{\tau_{y}}{P}\right)
$$

where $c=13,708$. This equation at high pressures shows that $m=0.188$ which is very close to the $m$ obtained in the empirical Eq. (6). Eq. (7) reduces to Eq. (5) for very small value of $P / \tau_{\mathrm{y}}$ and to Eq. (6) for large value of $P / \tau_{\mathrm{y}}$ with $m=$ 0.188 . The author also proposed an approximate version of Eq. (7) for quick calculations. This is given as

$$
h_{L}=\frac{2 r}{3}\left(\frac{\tau_{y}}{P}\right)+\left(\frac{c r}{1.5}\right)^{0.188} d^{0.811} \times\left(\frac{\tau_{y}}{P}\right)^{0.188}
$$

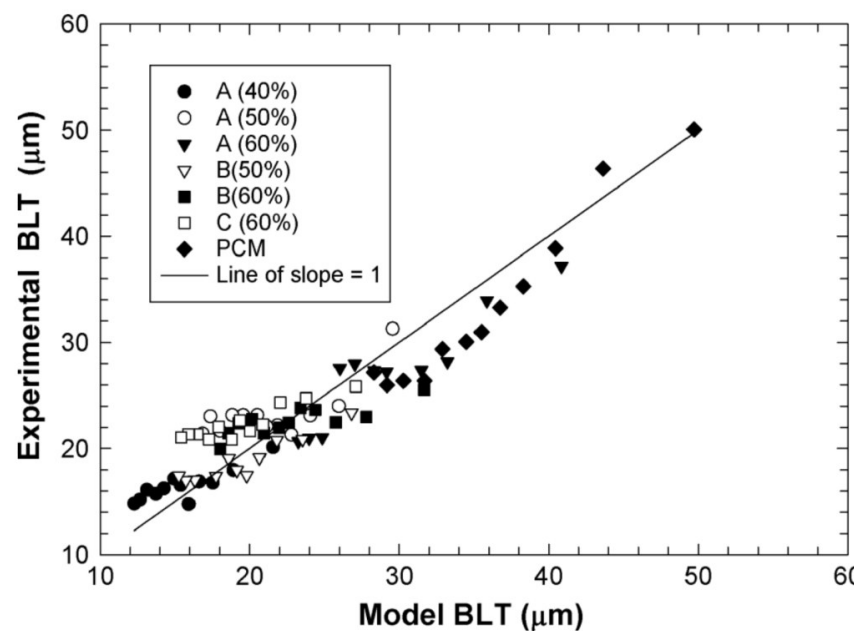

Fig. 3 Comparison of scaling bulk model with experimental data for the phase change material. (Reproduced with permission. ${ }^{22}$ Copyright 2006, IEEE)

Fig. 3 shows the comparison of Eq. (7) (S-B model) with experimental data obtained from various TIMs. ${ }^{22}$ The author also compared Eq. (7) with a variety of other suspensions for $d$ as large as $80 \mu \mathrm{m}$ and as small as $2 \mu \mathrm{m}$ and showed that Eq. (7) matches very well with the data. ${ }^{20}$ Eq. (7) can be applied to phase change material, greases, and pre-cure gels as these TIMs are well described by the H-B model.

\subsection{Effect of Particle Volume Fraction on Bulk TIM Thermal Resistance}

The bulk thermal resistance of the TIM is given by,

$$
R_{b u l k}=\frac{B L T}{\lambda_{T M}}
$$

By combining Eqs. (6) and (9), $R_{b u k}$ can be arranged as,

$$
R_{\text {bulk }}=\frac{1}{\lambda_{T I M}} C\left(\frac{\tau_{y}}{p}\right)^{m}
$$

If electrostatic interaction is assumed to be negligible compared to the Van der Waal's interaction in the particle laden polymer, then $\tau_{\mathrm{y}}$ can be expressed as, ${ }^{25}$

$$
\tau_{y}=A\left[\frac{1}{\left(\phi_{m} / \phi\right)^{1 / 3}-1}\right]^{2}
$$

where $A$ is constant, and $\phi_{m}$ is the maximum particle volume fraction. Eq.(11) can also be rearranged as,

$$
\tau^{\prime}=\frac{\tau_{y}}{A}=\left[\frac{1}{\left(\phi_{m} / \phi\right)^{1 / 3}-1}\right]^{2}
$$

where $\tau^{\prime}$ is the dimensionless yield stress. Using $\tau^{\prime}$, Eq. (10) can be written as, 


$$
\frac{R_{b u k k P^{m}}}{C A^{m}}=\frac{\tau^{\prime m}}{\lambda_{T I M}}
$$

Using the BAM and Eq. (13), Prasher et al. ${ }^{19}$ showed that $R_{\text {bulk }}$ reaches minima with respect to the volume fraction of the fillers. This was experimentally verified by them, as shown in Fig. 4.

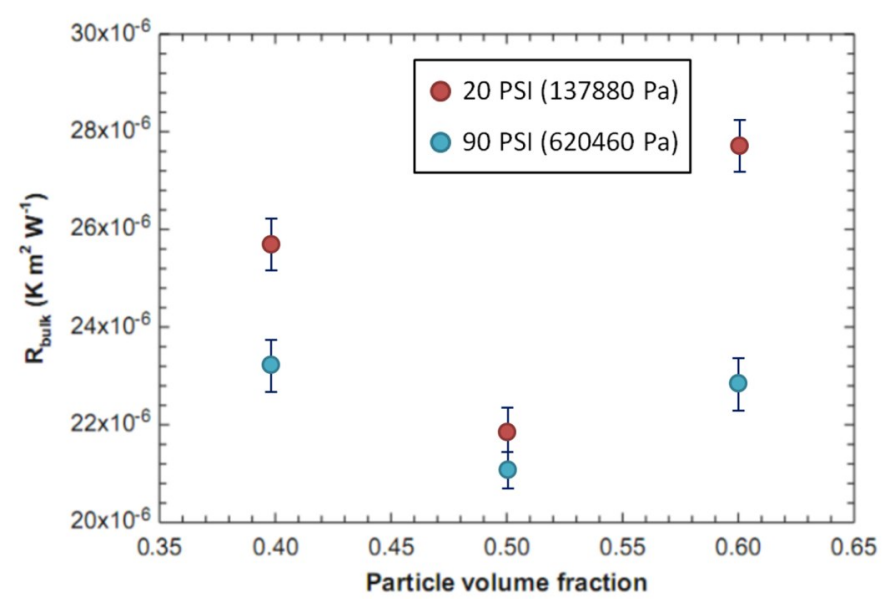

Fig. 4 Experimental results for resistance vs. particle volume fraction for silicone-based thermal greases. (Reproduced with permission. ${ }^{19}$ Copyright 2003, The American Society of Mechanical Engineers)

Fig. 4 shows that there is an optimal volume fraction for the minimization of the TIM thermal resistance. Prasher ${ }^{20}$ recently performed parametric studies on the thermal resistance for various factors such as $\phi$, diameter of the filler and the applied pressure. The key conclusion from Prasher's parametric study was that there is an optimal volume fraction for a given pressure and filler shape, above which thermal resistance of the TIM increases.

\subsection{Model to Predict Thermal Contact Resistance $(\mathrm{R} c)$}

Prasher ${ }^{17}$ proposed an incomplete wetting by applying surface chemistry and assuming pure liquid-like behavior for TIMs. This model assumed that the TIM is unable to fill all the valleys due to trapped gases in the valleys of the rough surface, as shown in Fig. 5. By applying force balance among the externally applied pressure, capillary force due to the surface tension of the TIM and back pressure due to the trapped air, it was possible to calculate the penetration length of the TIM in the interface. A constriction resistance parameter was defined based on $A_{\text {real }}$ and $A_{\text {nominal }}$ as shown in Fig. 5. For $\lambda_{T I M}<<$ $\lambda_{\text {substrate }}$, the surface chemistry model is given by

$$
R_{C_{1}+2}=\left(\frac{\sigma_{1}+\sigma_{2}}{2 \lambda_{\text {TIM }}}\right)\left(\frac{A_{\text {nominal }}}{A_{\text {real }}}\right)
$$

where $\sigma_{1}$ and $\sigma_{2}$ are the surface roughness of the two substrates sandwiching theTIM. $A_{\text {real }}$ can be calculated from penetration length of the TIM.

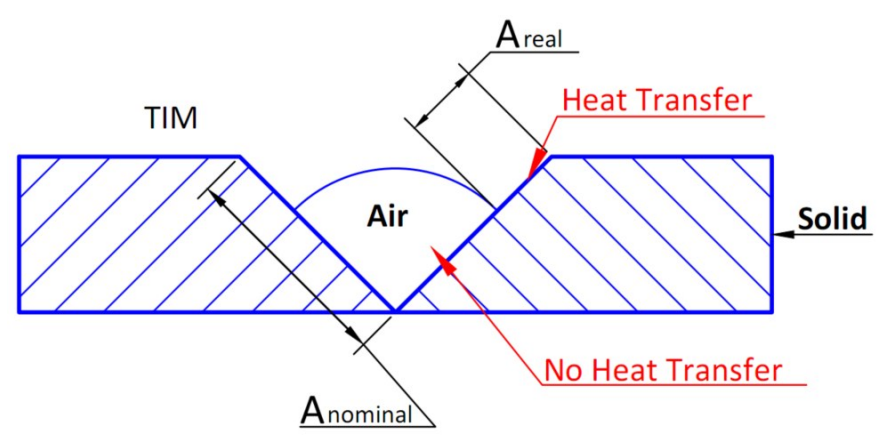

Fig. 5 Mechanism of heat transfer near the TIM substrate interface.

The surface chemistry model was in good agreement with PCM and greases as shown in Fig. 6. However, considering the later finding by Prasher ${ }^{19,20}$ that these TIMs possess yield stress and viscosity, which means that they are semi-solid and semiliquid, the pure liquid-based surface chemistry model is not good enough for the modeling of the contact resistance of TIMs.

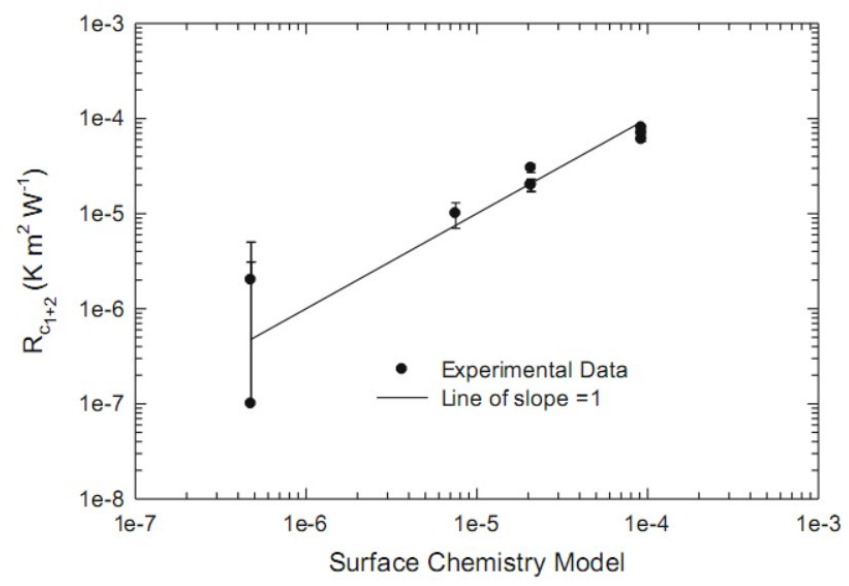

Fig. 6 Comparison of the surface chemistry model with experimental results for phase change materials. (Reproduced with permission. ${ }^{22}$ Copyright 2006, IEEE)

Intuitively speaking, the area covered by the TIM in the valleys of the interface as shown in Fig. 1 will eventually depend on the pressure and yield stress. This relation could be somewhat similar to that obtained for bare metallic contacts where the contact resistance depends on the pressure and the hardness of the softer material. For TIMs, most likely hardness will have to be replaced by the yield stress. Internal studies at Intel on various state-of-the-art TIMs have suggested, however, that bulk resistance of the TIM is more dominant than $R \mathrm{c}$. For cured gels, Prasher and Matyabus ${ }^{21}$ proposed a semi-empirical model for $R \mathrm{c}$, which has similar form as Eq. (1). This model is given as

$$
\frac{R_{C} \lambda_{T I M}}{\sigma}=\mathrm{c} \frac{G^{n}}{P}
$$


where $G=\sqrt{G^{2}+G^{\prime 2}}$. $G^{\prime}$ is the storage shear modulus and $G^{\prime \prime}$ is the loss shear modulus of the TIM. $G^{\prime}>G^{\prime \prime}$ is for cured gels, while $G^{\prime} \leqslant G^{\prime \prime}$ is for uncured gels that are nothing by greases. Fig. 7 shows the comparison of this model with experimental data from four gels with different formulations. Fig. 7(a) shows $R_{c}$ plotted against $G^{\prime} / P$, and there exists a strong correlation between and as all the data fall into a single curve when $R c$ is plotted against $G^{\prime \prime} / P$. Fig. $7(\mathrm{~b})$ shows $R_{c}$ plotted against $G^{\prime \prime} / P$, a strong correlation of with as well. $G$ is related to the ratio of the nominal area of contact and the real area of contact which is same as that for metals where the hardness of the material dictates the ratio of the nominal area of contact and the real area of contact.
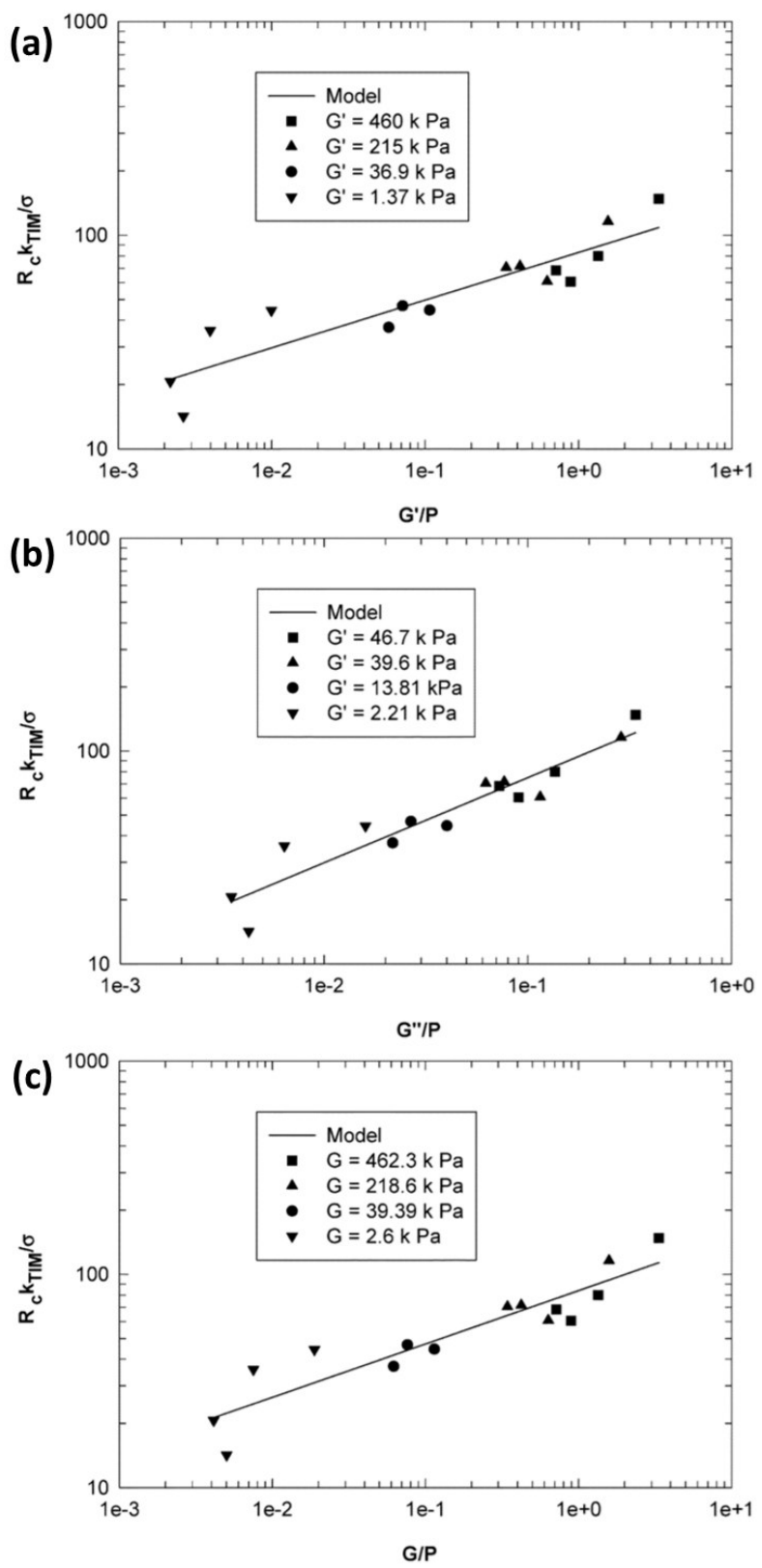

Fig. 7 (a) $R_{c} \lambda_{\mathrm{TIM}} / \sigma$ versus $G^{\prime} / P$, (b) $R_{c} \lambda_{\mathrm{TIM}} / \sigma$ versus $G^{\prime \prime} / P$, (c) $R_{c} \lambda_{\text {TIM }} / \sigma$ versus $G / P$ for TIM. (Reproduced with permission. ${ }^{21}$ Copyright 2004, IEEE)

\subsection{Reliability Consideration for Polymeric TIMs}

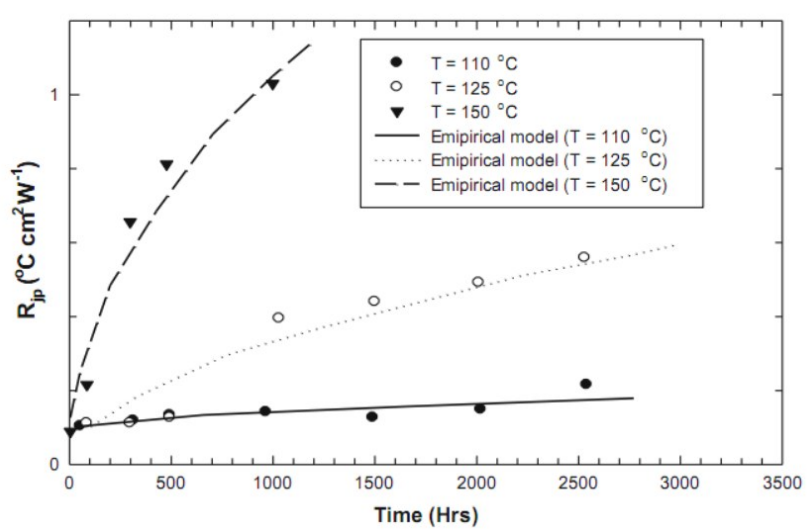

Fig. 8 Degradation of thermal resistance with time. Lines are the empirical curve fit of the form given by Eq. (16). (Reproduced with permission. ${ }^{22}$ Copyright 2006, IEEE)

Most research on polymeric TIMs until now has focused on the behavior of freshly made TIMs. In reality, these TIMs are likely exposed to high temperatures and harsh conditions during the product life time. Assuming that a product life is 7 years, this translates into approximately $61,000 \mathrm{~h}$ under continuous operation or $35,000 \mathrm{~h}$ for $14 \mathrm{~h}$ per day. If the product operation temperature is $100{ }^{\circ} \mathrm{C}$, then the polymers in the TIM are being exposed to relatively high temperatures for the product lifetime. Polymers degrade under such high temperatures. ${ }^{26}$ However, it is unlikely to test these TIMs for such long times to understand their behavior for exposure to high temperatures before launching the product. Therefore, to understand the degradation behavior, accelerated lifetime testing is performed. Under accelerated testing the TIM is exposed to much higher temperatures than the "use condition" (or operational) temperature. For example, if the product operation temperature is $100{ }^{\circ} \mathrm{C}$, TIM could be tested at $125^{\circ} \mathrm{C}$ and $150^{\circ} \mathrm{C}$ for a much shorter period of time than the product life. The thought behind this is that higher temperature will accelerate the degradation and engineers would be able to generate TIM degradation models in a limit time frame. Fig. 8 shows the thermal resistance $\left(R_{j c}\right)$ of a PCM TIM as a function of time and temperature. ${ }^{16}$ The lines represent an Arrhenius type model obtained by curve fitting empirical data to the following equation:

$$
R_{j c}(t)=R_{j c}(t=0)+A \sqrt{t} \exp \left(\frac{-E_{a}}{\lambda_{b} T}\right)
$$

where $E_{a}$ is the activation energy, $A$ is the acceleration factor and $\lambda_{b}$ is the Boltzmann constant, $t$ represents the time, and the first term on the right-hand side is the $R_{j c}$ value at $t=0$ (i.e., fresh TIM without exposing to high temperature). The research discussed in previous sections has focused on $R_{j c}$ at $t=0$. Eq. (16) shows some type of a diffusion process with a square root 
dependence ontime. ${ }^{26}$ Once $A$ and $E_{a}$ are obtained from matching the data at different (or higher) temperatures, the use temperature can be put into Eq. (16) to obtain the value of $R_{j c}$ at the use temperature and end-of-life of the product. In the industry, TIMs are typically designed for end-of-life performance so that it should be very careful to choose the appropriate TIM based on their reliability performance. This is because some TIM gives the best $R_{j c}$ at $t=0$, but that TIM might degrade so that at end-of-life it gives worse performance than the other TIMs.

There is no mechanistic understanding of the degradation of the thermal performance of the TIMs due to large exposures to high temperatures. Form of Eq. (16) suggests some type of diffusion process, however it is not clear what is really diffusing. Even if it is assumed that the oxidation of the TIMs follows a diffusion process, no attempt has been made to relate this to thermal performance. This area to research TIM reliability behavior is wide open. In addition to high temperature, thermal greases suffer from another type of degradation that is commonly known as pump-out..$^{15}$ Thermal grease pump-out typically occurs after temperature cycling or power cycling. Recently, Prasher and Matyabus ${ }^{21}$ related the pump-out problem to the ratio of $G^{\prime}$ and $G^{\prime \prime}$. They found that $G^{\prime}$ of grease should be greater than $G^{\prime \prime}$ to avoid pump-out. This is exactly what a gel does. Gel is nothing but a cured grease. Fig. 9 shows the rate of degradation of thermal performance vs. $G^{\prime} / G^{\prime \prime}$. It was observed that the degradation rate is approaching to a much lower constant after $G^{\prime}>G^{\prime \prime}$.

Current commercial TIMs can be divided into several categories, as each one has different properties and applications. A summary of the properties of different common TIM types is given in Table 3. Thermal grease-Thermal grease consists of thermally conductive filler in a silicone or hydrocarbon oil and has historically been widely used in industry. It conforms well to the substrates and can form thin BLT, leading to thermal interface resistance approaching 10 $\mathrm{Kmm}^{2} \mathrm{~W}^{-1}$ for the highest performing thermal greases. ${ }^{27}$ It is also cheap compared to other TIM types, hence its popularity. It is applied as a paste leading to a somewhat messy processing, which is one of the large drawbacks. Since it is in liquid form, it is affected by the pump-out effect, which negatively affects the reliability. Also specifically for thermal grease, the matrix surrounding the fillers preferentially flows out of the interface, leading to a dry-out of the interface. Thermal pads-like thermal grease, thermal pads consist of thermally conductive fillers in a polymer matrix. However, in the case of thermal pads, the polymer matrix is heavily crosslinked, leading to a solid pad, which is much easier to handle. This leads to corresponding weaknesses of thick BLT (around 200- $1000 \mu \mathrm{m}^{28}$ ) and requiring high pressure to properly conform to substrates. To be able to conform to the substrates, the softness of the pad is very important, and since higher filler fractions of conducting particles increase the stiffness of the composite, the overall performance is severely limited by this trade-off between softness and filler fraction. Phase change materials (PCMs) aim to combine the best properties of thermal grease and pads. It consists of a matrix material with a melting temperature between room temperature and operating temperature. This allows it to be handled like a pad, but melts during operation and is able to conform to the substrates and form thin BLT-like thermal grease. ${ }^{29,30}$ It is also possible to have a PCM with a melting temperature above the operating temperature, in which case the TIM is reflowed during processing and kept solid during operation.

Table 3 Common types of commercial TIMs and typical properties. ${ }^{27-38}$

\begin{tabular}{|c|c|c|c|c|c|c|c|}
\hline Type & $\begin{array}{l}\text { Thermal } \\
\text { conductivity } \\
\left(\mathrm{Wm}^{-1} \mathrm{~K}^{-1}\right)\end{array}$ & $\mathrm{BLT}(\mathrm{pm})$ & $\begin{array}{l}\text { Thermal } \\
\text { interface } \\
\text { resistance } \\
\left(\mathrm{Km}^{2} \mathrm{~W}^{-1}\right)\end{array}$ & Pump-out & $\begin{array}{l}\text { Absorbs } \\
\text { stress }\end{array}$ & Reusable & Replaceability \\
\hline Thermal grease & $0.4-4$ & $20-150$ & $10-200$ & Yes & Well & No & Medium \\
\hline Thermal pad & $0.8-3$ & $200-1000$ & $100-300$ & No & Well & Yes & Excellent \\
\hline Phase change material & $0.7-1.5$ & $20-150$ & $30-70$ & Yes & Well & No & Medium \\
\hline Thermal gel & $2-5$ & $75-250$ & $40-80$ & No & Medium & No & Medium \\
\hline $\begin{array}{l}\text { Thermally } \\
\text { conductive adhesive }\end{array}$ & $1-2$ & $50-200$ & $15-100$ & No & Medium & No & Poor \\
\hline Solder & $20-80$ & $25-200$ & $<5$ & No & Poorly & No & Poor \\
\hline
\end{tabular}


The most common type of TIM is thermally conductive PLPs, which includes most types of greases, pads, gels and PCMs. Filler particles greatly enhance the thermal conductivity of the polymer matrix, while retaining wetting and viscous characteristics from the polymer matrix. Its widespread usage in industry makes the road from research to industry short, and new progress can be introduced to the market relatively quickly. Relatively simple experimental procedures, combined with a large variety of potential filler candidates, have spurred a large number of publications, although the overall performance has not increased substantially in the last decade. PLPs typically come in a liquid form, and due to ease of measurement uncertainties during application, comparative values in the literature are generally based on the thermal conductivity rather than the thermal interface resistance during operation. Comparisons with other types of TIM necessitate the simulation of the other parameters of Eq. (1). Research presented in this review is focused on improving thermal conductivity, but it is important to consider other properties that will influence behaviour in a real application, primarily the viscosity. Another important parameter to consider in the context of particle fillers is the filler fraction, i.e. how much of the composite material consists of the conducting material. This is especially important when comparing research results, as a higher filler fraction obviously leads to better conductivity, but has severe drawbacks both in terms of cost and mechanical properties. Achieving a great performance boost at a very low filler fraction would be a significant achievement.

The filler fractions can be measured either as weight percentage or volume percentage. Weight fraction is much easier to measure, but the mechanical properties are generally more related to the volume fraction. There is no general guideline for what value should be reported, in some cases making it difficult to compare results with each other.

At a certain concentration of fillers, individual particles will be in contact with their neighbors, forming a network of conductive particles. This network formation is called percolation, and the critical filler fraction where it occurs is called the percolation threshold. Increasing the filler fraction above the percolation threshold allows for continuous heat paths, Fig. 9(b), abruptly increasing the composite thermal conductivity compared to a filler fraction below the percolation threshold Fig.9(a). Fillers with a high aspect ratio, Fig.9(c) and composite materials with fillers in different sizes, Fig.9(d) can help achieve percolation at lower total filler fraction.

Different materials used as fillers in PLPs can be seen in Table 4together with their thermal conductivity. Aside from the thermal conductivity, there are a number of parameters to consider for choosing material to suit different applications, such as electrical conductivity, thermal interface resistance between filler and matrix, and cost.

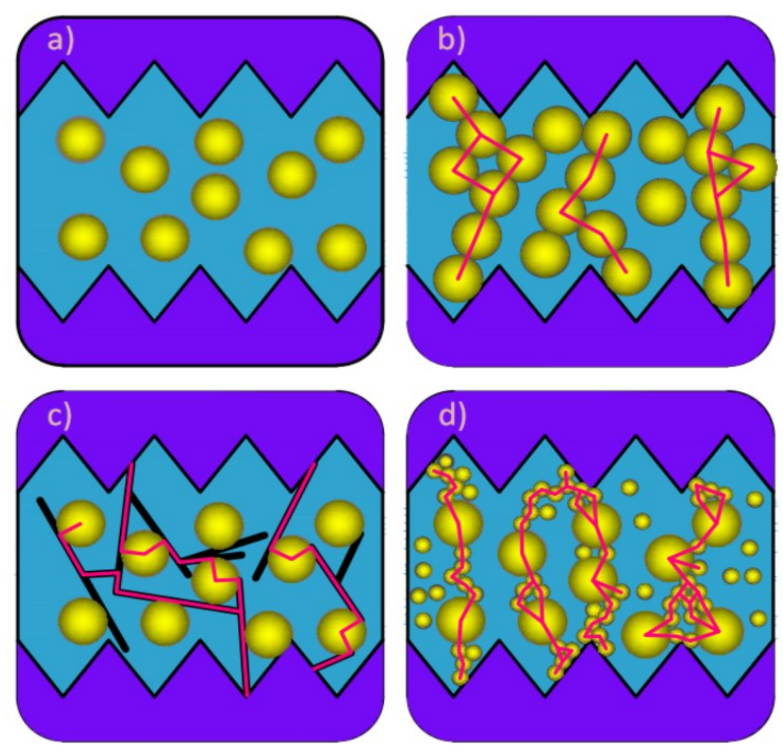

Fig. 9 Schematic representations of percolation concepts in PLPs. (a) PLP with filler fraction below the percolation threshold. (b) PLP with filler fraction above percolation threshold, allowing thermally conductive pathways to form. (c) Combination of fillers with high aspect ratio can achieve percolation at lower filler fractions. (d) Combination of fillers with different sizes can achieve percolation at lower filler fractions.

Table 4 Thermal conductivity of common types of fillers.

\begin{tabular}{ll}
\hline Material & Conduccivity $\left(\mathrm{W} \mathrm{m}^{-1} \mathrm{~K}^{-1}\right)$ \\
\hline Graphene & 600 \\
SWCNT & 3500 \\
MWCNT & 3000 \\
Diamond & 2000 \\
Graphite & $100-400$ (in-plane) \\
$\mathrm{BN}$ & $250-300$ \\
$\mathrm{Ag}$ & 427 \\
$\mathrm{Cu}$ & 393 \\
$\mathrm{Au}$ & 315 \\
$\mathrm{Al}$ & 237 \\
$\mathrm{BeO}$ & 218 \\
$\mathrm{AlN}^{\mathrm{N} N}$ & 170 \\
$\mathrm{Al}_{2} \mathrm{O}_{3}$ & 39 \\
$\mathrm{Zno}_{\mathrm{SiO}_{2}}$ & 21 \\
\hline
\end{tabular}

What type of filler to use in TIM depends on application. For instance, the most highly thermally conducting particles also conduct electricity which can be unsuitable in some applications and the mechanical properties of the TIM will 
Table 5 Summary of recent results in PLPs.

\begin{tabular}{|c|c|c|c|c|c|}
\hline Filler & Matrix & Filler fraction & $\begin{array}{l}\text { Thermal Conductivity } \\
\left(\mathrm{W} \mathrm{m}^{-1} \mathrm{~K}^{-1}\right)\end{array}$ & TCE $(\%)$ & Ref \\
\hline \multicolumn{6}{|l|}{ Carbon fillers } \\
\hline SWCNT & PMMA & 7 vol- $\%$ & 0.35 & 55 & [39] \\
\hline SWCNT & Polystyrene & $1 \mathrm{wt}-\%$ & 0.25 & 50 & {$[40]$} \\
\hline SWCNT & PMMA & $1 \mathrm{wt}-\%$ & 2.43 & 880 & {$[41]$} \\
\hline MWCNT & Silicone & 2 wt- $\%$ & 0.315 & 19 & {$[42]$} \\
\hline MWCNT & PMMA & 4 wt- $\%$ & 3.44 & 1276 & {$[41]$} \\
\hline MWCNT & Silicone & $2 \mathrm{wt}-\%$ & 4.267 & 522 & {$[43]$} \\
\hline $\mathrm{MWCNT} / \mathrm{Al}_{2} \mathrm{O}_{3}$ clusters & Epoxy & 0.15 wt- $\%$ & 0.39 & 130 & {$[44]$} \\
\hline $\mathrm{Ag}$ plated $\mathrm{CNF}$ & Epoxy & $4.5 \mathrm{wt}-\%$ & 2.33 & 1165 & {$[45]$} \\
\hline $\mathrm{CNF}$ & FKM & $13.2 \mathrm{wt}-\%$ & 21 & 10986 & {$[46]$} \\
\hline GNP & Epoxy & 25 vol- $\%$ & 6.44 & 3000 & {$[47]$} \\
\hline GNP & Silicone & $20 \mathrm{wt}-\%$ & 2.3 & 752 & {$[48]$} \\
\hline Graphite & Epoxy & $20 \mathrm{wt}-\%$ & 5 & 2400 & {$[49]$} \\
\hline Graphene & Epoxy & 10 vol- $\%$ & 5 & 2300 & {$[50]$} \\
\hline Graphene & Epoxy & $30 \mathrm{wt}-\%$ & 4.9 & 1900 & {$[51]$} \\
\hline \multicolumn{6}{|l|}{ Ceramic fillers } \\
\hline $\mathrm{BN}$ & Epoxy & 20 wt- $\%$ & 0.9 & 3350 & {$[52]$} \\
\hline $\mathrm{BN}$ & Epoxy & 70 wt- $\%$ & 5.24 & 1800 & {$[53]$} \\
\hline $\mathrm{BN}$ & Epoxy & 70 wt- $\%$ & 3.1 & 1550 & {$[54]$} \\
\hline $\mathrm{BN}$ & HDPE & 50 vol- $\%$ & 4.5 & 800 & {$[55]$} \\
\hline $\mathrm{BN}$ & Silicone & 60 vol- $\%$ & 1.2 & 500 & {$[56]$} \\
\hline $\mathrm{BN}$ & Silicone & 9.14 vol- $\%$ & 0.6 & - & {$[57]$} \\
\hline AIN & Epoxy & 60 vol- $\%$ & 2.7 & 1200 & {$[58]$} \\
\hline AIN & Epoxy & $30 \mathrm{wt}-\%$ & 0.24 & 52.5 & {$[59]$} \\
\hline \multicolumn{6}{|l|}{ Metal fillers } \\
\hline AgNP network & Epoxy & 45 vol- $\%$ & 27 & 13400 & {$[60]$} \\
\hline $\mathrm{AgNW}$ & Polycarbonate & 9 vol- $\%$ & 30.3 & - & [61] \\
\hline $\mathrm{AgNW}$ & Silicone & $7.2 \mathrm{wt}-\%$ & 0.19 & - & {$[62]$} \\
\hline $\mathrm{CuNW}$ & Acrylate & 0.9 wt- $\%$ & 2.46 & 1350 & {$[53]$} \\
\hline AuNW & Silicone & 3.3 vol- $\%$ & 5 & 2900 & {$[63]$} \\
\hline Liquid Ga & Silicone & 92.5 wt- $\%$ & 2.2 & 1194 & {$[64]$} \\
\hline $\mathrm{FeCr} / \mathrm{Al}_{2} \mathrm{O}_{3}$ shell & $\mathrm{CPE}$ & 70 vol- $\%$ & 4 & - & {$[65]$} \\
\hline \multicolumn{6}{|l|}{ Hybrid filler combinations } \\
\hline $\mathrm{BN} / \mathrm{CNF}$ & Epoxy & $6 / 8$ wt- $\%$ & 0.6 & 750 & {$[66]$} \\
\hline $\mathrm{BN} / \mathrm{MWCNT}$ & Epoxy & $30 / 1$ & 1.912 & 743 & {$[67]$} \\
\hline $\mathrm{BN} / \mathrm{MWCNT}$ & Polyethylene & $50 / 1 \mathrm{wt}-\%$ & 1.641 & 323 & {$[68]$} \\
\hline MWCNT/GO & Epoxy & $50 / 0.36$ wt- $\%$ & 4.7 & 2250 & [69] \\
\hline MWCNT/GO & PEEK & $0.45 / 1 \mathrm{wt}-\%$ & 0.44 & 145 & {$[70]$} \\
\hline GNP/Carbon Black & Epoxy & $14 / 4 \mathrm{wt}-\%$ & 0.81 & 305 & {$[48]$} \\
\hline Graphene $/ \mathrm{Al}_{2} \mathrm{O}_{3}$ & Silicone & $1 \mathrm{wt}-\% / 63$ vol- $\%$ & 3.45 & 2553 & {$[71]$} \\
\hline
\end{tabular}


increasingly depend on the filler particle properties at higher filler fractions. The most common types of fillers investigated are presented in Table 4.
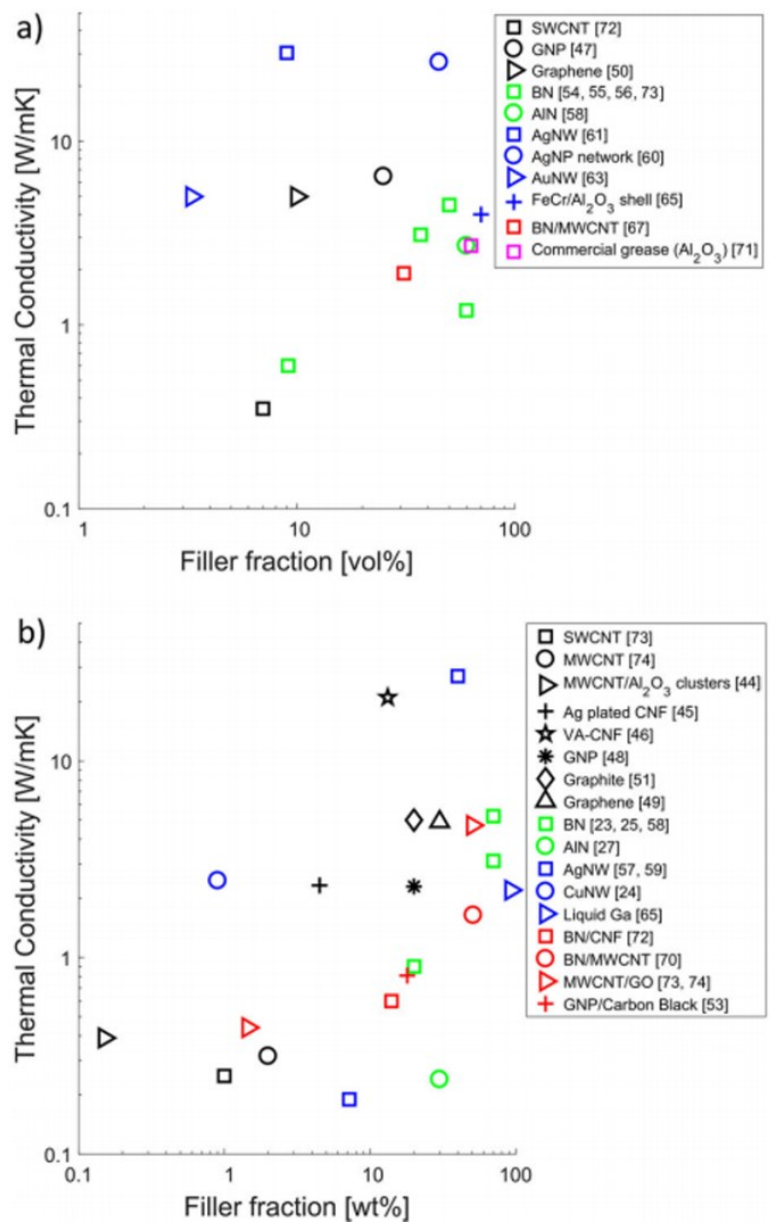

Fig. 10 Summary of reported values of thermal conductivity of PLPs versus the filler fraction, divided into groups: carbon allotropes black), ceramics (green), metal (blue) and hybrid filler combinations (red). Included is also the value for a commercial thermal grease (magenta). The values are divided into two graphs depending on if (a) filler volume fraction or (b) filler weight fraction was reported. (Reproduced with permission..$^{10}$ Copyright 2018, Taylor \& Francis)

Recent progress in PLPs is summarized in Table 5, with filler combination, matrix material, filler fraction, thermal conductivity and thermal conductivity enhancement (TCE), i. e. the improvement in thermal conductivity versus the base matrix material. Also, reported thermal conductivity values versus filler fraction are shown in Fig. 10. The figure is split into two graphs as filler fraction value reported is alternatively given in volume fraction or weight fraction. The volume fractions give a more accurate representation of the effect of higher filler fractions, but general trends can be distinguished in both cases. It is clear that alignment of high-aspect ratio fillers such as carbon nanofibers and metal nanowires can provide a magnitude higher thermal conductivity at the same filler fraction compared to unaligned fillers, and is generally the only way to increase the thermal conductivity beyond 10 $\mathrm{W} / \mathrm{mK}$. Also noteworthy is that although CNTs have shown rather unimpressive performance as fillers, other carbon allotropes, such as graphene and GNP, have shown better performance than other kinds of fillers at similar fractions. Aside from these few exceptions, the actual performance of PLPs has not increased significantly during the last decade, and recent reports have similar performance to commonly available industrial TIMs. Part of the reason for the continued high research interest might be that researching new filler combinations is relatively easy compared to other types of TIMs, rather than actual potential for further research. Still, by combining high aspect ratio fillers with alignment methods, there might be a potential for a true breakthrough.

The current industry is dominated by PLPs in different varieties, and there is a large infrastructure already in place for developing new compounds. This means that any breakthrough in research has the potential to quickly reach the market. The matrix material has little effect on the thermal conductivity, allowing filler development to have an effect on a wide range of TIMs.

\section{Organic-Inorganic Composites of TIM}

Common polymers have low thermal conductivities, they cannot effectively dissipate heat when being used in various devices and their high thermal expansion coefficients result in thermal failure. Organic-inorganic composites of TIM have attracted increasing attention. They have also gained wide applications in various branches of industry because of their low density, ease of formation, chemical inertia, low cost, and electrical insulation. By adding thermal conductive fillers to polymers, the thermal behavior of packaging materials can be improved remarkably. The literatures concerning thermal conductive polymer composites are particularly focused on the use of different kinds of ceramics or carbon nanofiber. Different nanoparticles have been used to improve the thermal conductivity of polymers. However, in most of these papers, thermal and other properties are still not good enough. Therefore, there is a need for improvement, whereby there will be a balance point for both electrical and thermal management. The thermal conductivities of all composites greatly depend on the properties of polymers and fillers, such as their content, components, and the surface treatment of filler. Have to point out is that it is disfigurement such as air hole, impurity etc. in composites that is a very important factor to account the effective thermal conductivity of composites.

\subsection{Polymeric Matrix Materials}

The thermal conductivity of polymers has been traditionally enhanced by the addition of high thermally conductive fillers, including graphite fillers, carbon black fillers, carbon fibers 
fillers, ceramic fillers and metal fillers, and so on. These fillers possess very high thermal conductivity, some even as high as several thousand $\mathrm{W} / \mathrm{mK}$, e. g. CNT, diamond. Thermal conductivity of composite can be improved remarkably by adding thermal conductive fillers to polymer. High filler loadings ( $>35$ vol $\%)$ are typically necessary to achieve the appropriate level of thermal conductivity in thermally conductive polymer composites, which represents a significant processing challenge. Moreover, high inorganic filler loading also dramatically alters the polymer mechanical behavior and density while increasing thermal conductivity of composites. For these reasons, obtaining composites having thermal conductivities higher than $4 \mathrm{~W} / \mathrm{mK}$ and usual polymer process ability are very challenging at present. A common trait among all polymer matrices is the low thermal conductivity, which varies between 0.1 and $0.3 \mathrm{~W} / \mathrm{mK}$. While a large number of matrix materials can be used, most research is done on one out of two main types of polymers: epoxy and silicone oil. The main difference is that epoxy functions as an adhesive, and can be used for die attach applications while silicone oil needs external clamping. Silicone oil is the base material of many common types of thermal grease.

\subsection{Ceramics}

Ceramics have the additional advantage of being electrically insulating, which limits the application of the other groups. Out of the ceramics, BN has the highest thermal conductivity, and even higher thermal conductivity has been reported for very thin sheets, making it an increasingly interesting material for thermal management applications. As early as 1998, Ishida et $a l .{ }^{76}$ reported a thermal conductivity value of $32.5 \mathrm{~W} / \mathrm{mK}$ for BN-filled polybenzoaxine which still stand as the highest value to date, although at a very high filler fraction ( $88 \mathrm{wt} \%$ ). It has more recently been investigated further in silicone thermal $\operatorname{pads}^{56}$, epoxy ${ }^{54,75}$ and other polymer matrices. ${ }^{52,55}$ Another ceramic which has attracted academic interest is AlN ${ }^{58,59}$ which is also together with $\mathrm{Al}_{2} \mathrm{O}_{3}$ popular in commercial applications.

\subsection{Metals}

Metals have very high intrinsic bulk thermal conductivity and good handling properties. The best commercially available thermal greases have a thermal conductivity of about $8 \mathrm{~W} / \mathrm{mK}$ with a filler of Ag flakes. Most recent progress using metal fillers is focused on using metal nanowires (NWs) rather than spherical fillers. A reason for the perceived promise of CNTs is the 1D structure which allows for percolating net- works at a much lower filler fraction than spherical fillers. Metal nanowires have a similar 1D structure, and can improve the thermal conductivity drastically at very low filler fractions. Ag is the most popular metallic filler in commercial compounds and is a natural candidate, and has been demonstrated as TIM filler by electrodeposition of a template ${ }^{61,77}$ or a chemical process. ${ }^{62,53}$ The electrodeposition method forms a highly aligned network, which allows for a significantly higher thermal conductivity than using a random dispersion, $30.3 \mathrm{~W} /$ $\mathrm{mK}^{61}$ compared to $1.4 \mathrm{~W} / \mathrm{mK} .{ }^{53}$ In addition to these methods, Pashayi et al. demonstrated a self-structured metallic nanowire network based on agglomeration and sintering of PVP-coated Ag-nanoparticles which exhibits a thermal conductivity of up to $38.5 \mathrm{~W} / \mathrm{mK}$ at $48 \mathrm{vol} \%{ }^{60,78}$ Other metals have also been investigated. Wang et al. found that CuNWs gave a larger conductivity enhancement at a lower filler fraction than AgNWs, and achieved a thermal conductivity of $2.46 \mathrm{~W} / \mathrm{mK}$ at a low filler fraction of $0.9 \mathrm{wt} \%{ }^{53}$ Other investigated metals are $\mathrm{Ni}^{79,80}$ and $\mathrm{Au}^{63}{ }^{63}$ In addition to the work on nanowires, there has been work done to decrease the metal-polymer contact resistance using modified $\mathrm{FeCr}$ nanoparticles with a nanoporous $\mathrm{Al}_{2} \mathrm{O}_{3}$ shell to decrease the phonon scattering at the particle-matrix interface. ${ }^{65}$ Also, Jeong et al. ${ }^{64}$ recently introduced a concept of liquid metal fillers in PDMS matrix in order to allow thermally conductive, yet flexible and stretchable thermal elastomers to be produced.

\subsection{Hybrid Fillers}

A method of increasing the thermal conductivity at a lower filler fraction is to combine different fillers into the same TIM matrix, i.e. hybrid fillers. Different fillers create synergistic effects that increase the effective thermal conductivity beyond what would be expected from models. The most common mechanisms behind the synergistic effects are size variations of fillers, which can help forming percolating networks (see Fig. 9) and improve packing ratio,,$^{50,55,81}$ or variations in aspect ratio wherein the percolation-forming networks formed by high aspect ratio fillers can be combined with the bulk thermal transport properties of bulk and 2D fillers. ${ }^{82}$ Hybrid filler combinations reported typically include filler materials with different dimensionality (1D, 2D or 3D). Lee et al. demonstrated the concept of mixing 1D rods with spherical particles $^{83}$ in 2006. Recent progress includes studies of BN/ MWCNTs, ${ }^{67,68,84} \mathrm{BN} / \mathrm{CNFs}^{66}$ and $\mathrm{GO} / \mathrm{CNT}^{69,70}$ hybrid composites, which all combine $1 \mathrm{D}$ and 2D fillers, which are more effective for creating conducting networks than 1D/ spherical filler combination. ${ }^{68}$ Since spherical 3D and 2D flake fillers already exist as commercial compounds, the addition of a high aspect ratio filler into commercial thermal grease has proved a popular method of investigating the synergistic effects of spherical/high aspect ratio hybrid fillers. ${ }^{50,71,85,86}$ Among these, the highest thermal conductivity value reported to date can be found, at $14 \mathrm{~W} / \mathrm{mK}$, by the addition of an optimised mixture of graphene and multilayer graphene into thermal grease at a low filler fraction of $2 \mathrm{vol} \%{ }^{50}$ Also, the addition of MWCNTs to thermal grease has been directly shown to decrease the temperature of a running microprocessor. ${ }^{86}$ 


\subsection{Carbon Nanotube Array TIMs}

CNTs have had limited success as fillers in PLPs, due to high thermal contactresistance between individual CNTs. An array of vertically aligned CNTs spanning the whole gap between substrates would eliminate all internal interfaces and could be apractical way of harnessing the high thermal performance of CNTs in a TIM application. ${ }^{87}$ Different possible configuration of CNT array TIMs are shown in Fig. 5. A carbon nanotube array TIM consists of an array of CVD-grown CNTs on the growth substrate and in contact under pressure with a second substrate as seen in Fig. 11(a). The thermal interface resistance of CNT array TIM depends, as seen in Eq. (1), on the thermal contact resistance at the growth substrate and at the connecting substrate, as well as the inherent thermal conductivity of the CNT array. The CNT array thermal conductivity, in turn, depends on the thermal conductivity of each individual CNT and the CNT density in the array. At the growth substrate, each CNT has a connection, while at an opposing substrate only a fraction $\sigma$ of all CNTs will effectively contribute to thermal transport. Each parameter will be discussed in the following section. The thermal conductivity of a carbon nanotube can reach as high as $3000 \mathrm{~W} / \mathrm{mK}^{88,89}$ but the bulk value for CNT arrays is much lower, both due to low CNT density and defects and imperfections in the CNTs themselves. ${ }^{90}$ Thermal conductivity measurements have been reported as high as 267 $\mathrm{W} / \mathrm{mK}$, at filling fraction of about $10 \%,{ }^{91}$ corresponding to an individual CNT conductivity close to the highest values reported. More typical value for a CNT array, however, is on the order of $10 \mathrm{~W} / \mathrm{mK} .{ }^{90}$ While there is a large discrepancy between measured and theoretical thermal conductivity values, at moderate bond lines $(<30 \mu \mathrm{m})$ the thermal conductivity will have relatively low effect on the thermal interface resistance compared to the contact resistances. ${ }^{92}$ The thermal interface resistance components for a Si-CNT-Ag interface at $0.241 \mathrm{MPa}$ were measured by a photo acoustic method. While the contact resistance was $1.7 \mathrm{Kmm}^{2} / \mathrm{W}$ at the Si-CNT and $14 \mathrm{Kmm}^{2} / \mathrm{W}$ at the CNT-Ag interface, the thermal resistance from the bulk CNT array was less than $0.1 \mathrm{Kmm}^{2} / \mathrm{W} .^{93}$ This result, as well as others, ${ }^{91,94}$ shows that the contact resistances are dominating, and that the thermal contact resistance between the CNT tips and opposing substrate is about an order of magnitude higher than the resistance between the CNT roots and growth substrate. The large difference in contact resistance at the two sides is mainly attributed to a relatively low fraction of CNTs in contact with the opposing substrate, at about $15 \%$ of CNTs. The inter-CNT thermal conduction has been found to be negligible, and only the CNT in contact with both surfaces significantly contributes to the thermal transport. ${ }^{94,95}$ Another contributing factor is relatively well-connected CNTs at the substrate side, with each CNT covalently bonded to the catalyst particles, ${ }^{96}$ compared to weak van der Waals forces bonding at the tips. Depending on the catalyst deposition method, a weak adhesion between catalyst particles and substrate can also significantly contribute to the total contact resistance, as shown by Panzer et al. ${ }^{95}$ where dip-coated catalyst deposition resulted in much higher contact resistance than with PVD deposition. The low fraction of connecting CNTs creates a pressure dependence on the thermal interface resistance for CNT array due to the buckling of individual CNTs which allows additional CNTs to come into contact with the substrate. ${ }^{97}$ This makes the modulus of the CNT array an important parameter to control. At the interface between an individual CNT and substrate, there is also a Kapitza resistance. Li et al. conducted an investigation into the boundary resistance between CNTs and various metals and polymers. ${ }^{98}$ Interestingly, the thermal boundary resistance was shown to be significantly lower at the CNT-polymer interface than at the CNT-metal interface, which is attributed to a larger overlap of low-frequency vibration modes for polymers, which is lacking for metals. The result suggests that bonding with polymers might be a way towards lower thermal boundary resistance, despite the poor thermal conductivity of the polymers themselves. In an effort to eliminate the tip-substrate interface, $\mathrm{CNT}$ arrays can be grown on both mating substrates, effectively replacing the tip substrate interface with a CNT-CNT interface and a second root-substrate interface. The result can be seen in Fig. 11(b). The resulting thermal resistance value for a Si-CNT-CNT-Cu interface is substantially lower than for Si-CNT-Cu dry contact, ${ }^{93}$ but the CNT-CNT interface still shows a significant contact resistance. ${ }^{99}$ (a)

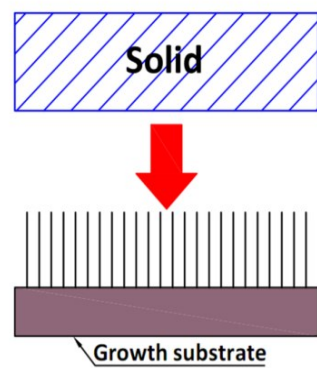

(c)

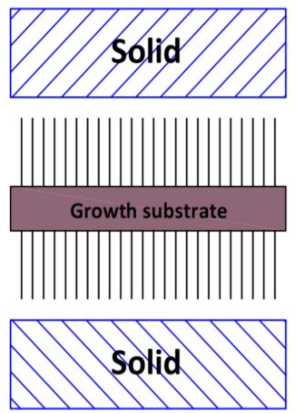

(b)

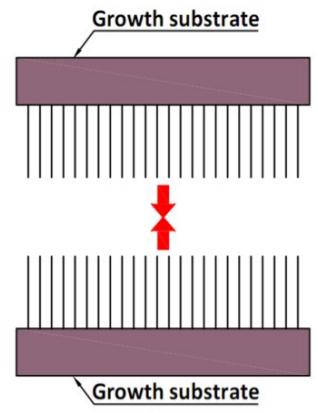

(d)

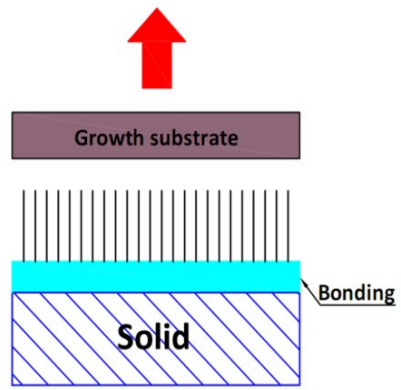

Fig. 11 Schematic diagrams of CNT array interface structures. (a) one-sided interface. (b) two-sided interface. (c) CNT-coated foil interface. (d) Bonding of CNT arrays to another substrate using metal or chemical bonding. 


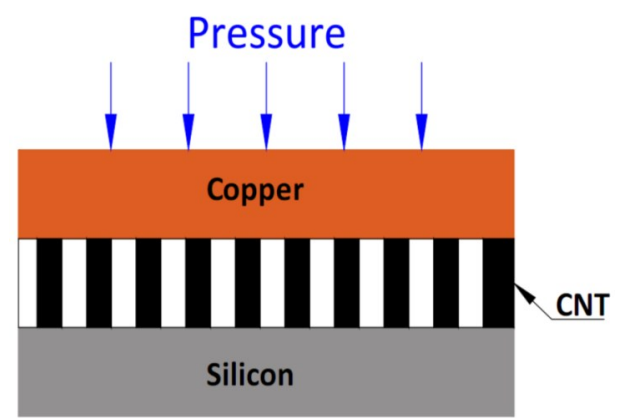

Fig. 12 Schematic showing of the use of carbon nanotube (CNT) grown in the back of Silicon.

Ever since carbon nanotube $(\mathrm{CNT})^{100}$ was demonstrated to have very high thermal conductivity, various CNT-based composites have been proposed and evaluated. ${ }^{101-104}$ Although CNTs are promising candidates as TIM fillers, CNTs have big limitation that interface resistance plays a significant role due to large inherent conductivity of the CNT. ${ }^{105}$ Huxtable et al. ${ }^{106}$ have experimentally measured $\mathrm{Rb}$ between CNTs and various liquids, showing that $\mathrm{Rb}$ is substantial $\left(8.33 \times 10^{8} \mathrm{~K} \mathrm{~m}^{2} \mathrm{~W}^{-1}\right)$. Prasher et al.$^{107}$ recently calculated the interface resistance of multiwalled CNT (MWCNT) for both horizontal and vertical contacts and showed the MWCNTs behave as graphite. Prasher's calculation shows the contact resistance of the vertical contact is smaller than the contact resistance of horizontal contact. Nan et al. ${ }^{105}$ recently proposed simplified effective medium model to compute $\lambda$ of CNT-based composites. Hu et al. ${ }^{108}$ have performed a feasibility study of CNT-based TIM, showing the potential of achieving percolation threshold at very small volume fraction. Another concern of CNT-based TIM is that the BLT of there sultant TIM will be high due to the high yield stress of fiber-based composites. Therefore, the overall thermal resistance is the more appropriate metric as compared to $\lambda_{\text {TIM }}$ for a fair comparison between CNT-based TIMs andconventional TIMs.

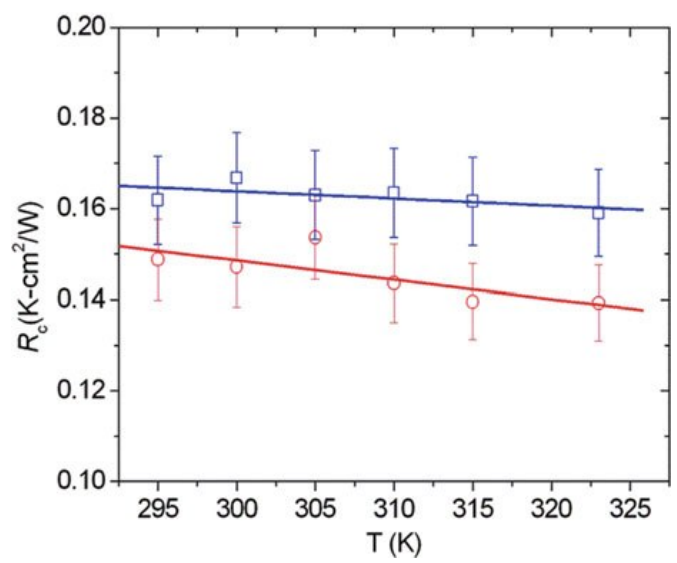

Fig. 13 Measured contact thermal resistance between the CNT sample and the experimental contact. (Reproduced with permission. ${ }^{110}$ Copyright 2006, The American Society of Mechanical Engineers)
$\mathrm{Xu}$ and Fisher ${ }^{109}$ have grown CNTs directly on the back of $\mathrm{Si}$, and then pressed a heat spreader against the as-grown CNTs. Fig. 12 shows the schematics of their concept. They have also combined PCM TIM and as-grown CNT to reduce the thermal resistance. Thermal resistance for this concept was experimentally measured by $\mathrm{Hu}$ et al., ${ }^{110}$ as shown in Fig. 13. At this time there is no physics based model for this concept. However, vertically grown CNT-based TIM looks promising. It seems that this concept will not suffer from the reliability problems that occur on polymer-based TIMs if this concept does not combine polymers.

This concept has good potential and could lead to various creative ideas, such as those shown by $\mathrm{Xu}$ and Fisher, ${ }^{111}$ where they used PCM TIMs in combination with vertically grown CNT or that by Tong et al. ${ }^{112}$ where they used thin layer of Indium in combination with vertically grown CNT. Wasniewski ${ }^{113}$ and Barako ${ }^{114}$ extended Tong's concept by making metallically bonded CNT and solder bonded CNT, respectively, significantly reducing thermal boundary resistance by up to a factor of 30 over a dry unbonded contact. Additional CNT-related development work includes bilayer aligned CNT (BACNT), ${ }^{115}$ a composite incorporated with nanocopper particles and MWCNT, ${ }^{116}$ transferred VACNT, ${ }^{117}$ and reactive metal bonding VACNT. ${ }^{118}$

In addition to CNT, researchers also proposed nanoparticles as TIM fillers. ${ }^{119,120}$ However, nanoparticles suffer from the same problem as CNTs because Rb plays a dominant role in nanoparticles-based composites. Putnam et al. ${ }^{121}$ measured $\mathrm{Rb}$ between polymer and alumina in the range of $2.5 \times$ $10^{8}$ to $5 \times 10^{8} \mathrm{Km}^{2} \mathrm{~W}^{-1}$. This means that the critical radius $(\alpha=1)$ below which the thermal conductivity of the nanocomposite is less than the conductivity of the matrix varies between 5 and $10 \mathrm{~nm}$. The yield stress of particle-laden polymers increases with decreasing particle diameter, ${ }^{25}$ leading to higher BLT for nanoparticle-based TIM than conventional TIMs. Therefore, it is not clear if nanocomposites can really be of great use as TIM fillers at this moment. In addition to nanoparticles, nanostructured polymer is used as a metal matrixcarrier (MMC) to form a composite with solder. Carlberg ${ }^{122}$ used electrospun polymer film consisting of a highly porous network of $2 \mu \mathrm{m}$-diameter fibers and $\mathrm{In} / \mathrm{Bi} / \mathrm{Sn}$ alloy to form a composite, resulting in thermal conductivity of $8 \mathrm{~W} / \mathrm{mK}$.Zanden ${ }^{123}$ used electrospinning polymide fiber film to form a composite with Indium solder, resulting in thermal conductivity up to $22 \mathrm{~W} / \mathrm{mK}$. MMC is a promising approach to enhance the possibility of integrating solders for TIM applications. ${ }^{124}$

Graphite nanoplatelet (GNP) is also a very efficient filler for epoxy composites. When embedded in an epoxy matrix, even loading of $25 \mathrm{vol} \%$ can surpass the performance of conventional fillers that requires a loading of $70 \mathrm{vol} \%$ to achieve the same thermal conductivity. ${ }^{125}$ When GNP is 
compared to Carbon Black (CB), in spite of high thermal conductivity of GNP, the effectiveness of GNP is limited due to its high BLT than CB. ${ }^{126} \mathrm{Xiang}^{127}$ investigated exfoliated GNP in improving thermal conductivity of PCM. With only 5 vol\% of GNP, thermal conductivity of $2.4 \mathrm{~W} / \mathrm{mK}$ can be achieved. Shtein ${ }^{128}$ applied high compression force to close the gaps between adjacent GNP, resulting in a GNP-based composite with a thermal conductivity of $12.4 \mathrm{~W} / \mathrm{mK}$.

Graphene, multilayer grapheme, ${ }^{129}$ hybrid graphene-metal composites $^{130}$ also provide thermal conductivity up to 5.1 and $9.9 \mathrm{~W} / \mathrm{mK}$, respectively. Theoretical consideration indicates graphene-based TIM can outperform those with CNT, nanoparticles due to its geometry, mechanical flexibility, and low Kapitza resistance.

\section{Characterization of TIM Thermal Performance}

Characterization of thermal interface materials in electronic applications is necessary to ensure timely product launches. This section will briefly review the methodology to test TIM. Many TIM testing apparatuses ${ }^{131,132}$ have been developed based on ASTM D5470-93. ${ }^{133}$ This testing apparatus can be used as a simple incoming TIM monitor or a quick benchmarking tool for new TIM without having to go through the time and expense of completing package level measurements. The tester was typically designed to test materials either at a controlled bondline thickness (e.g., using spacers ${ }^{134}$ ) or at a controlled pressures, while being able to directly measure the bondline thickness by using a laser micrometer, ${ }^{135}$ an optical micrometer ${ }^{136}$ inductive sensors, ${ }^{122}$ or a strain gage sensing the deformation induced by the distance change between the two mating surfaces. ${ }^{137}$ Chiu et al. ${ }^{133}$ have demonstrated that the tester is capable of evaluating TIM thermal impedance with a reproducibility of $0.03{ }^{\circ} \mathrm{C}-\mathrm{cm}^{2} / \mathrm{W}$ at a $95 \%$ confidence level. The testing apparatus was further modified for experimental validation of TIM characteristics between non-flat surfaces by Chiu et al. ${ }^{133}$

In addition to the steady-state measurement by ASTM D5470-93, several transient thermal analysis techniques including laser flash ${ }^{138,139}$ were also used for TIM characterization. A comparison between steady-state and transient methods can be found in Smith. ${ }^{139}$ In addition, photoacoustic (PA) technique, ${ }^{140}$ the $3 \omega$ method, ${ }^{141}$ transient thermo-reflectance (TTR), ${ }^{142}$ infrared microscopy, ${ }^{143}$ and Parker's method (with a hot plate and an IR camera) ${ }^{144}$ were widely used for TIM characterization. However, all these methodologies cannot capture the interaction of TIM with the actual packages and heat sinks in the application environment. Several papers have described how to characterize TIM behavior by using different thermal test vehicles. ${ }^{145-147}$ In order to understand reliability performance of TIM, Chiu et al. ${ }^{148}$ used an accelerated reliability test method to predict thermal grease pump-out in Flip-Chip applications. Morris ${ }^{149}$ tested several TIMs between heat sinks and IGBT modules under realistic Power Cycling conditions for final material selection. Bharatham et al ${ }^{150}$ studied the impact of different application pressure on a phase-change TIM on a bare-die FCBGA (Flip Chip Ball Grid Array) package with a heat sink solution. Due ${ }^{151}$ reviewed the commonly used reliability tests for TIM, including elevated temperature and humidity stress test, high temperature storage (or Bake), temperature cycling (TC), and power cycling (PC). In addition, forced mechanical cycling (FMC),pre-conditioning, thermos-gravimetric analysis (TGA), differential scanning calorimetry (DSC) are also applicable tests for TIM. ${ }^{151}$ All these testing methods were used to capture the possible reliability issues which are hard to predict by theory or numerical modeling. It is very important for a packaging engineer to validate TIM performance on the actual product with various reliability tests before launching the products.

\section{Summary and Outlook}

This article reviews the status of worldwide research on the thermal conductivity of TIM, meanwhile gives some insights into the effects of modified different fillers to improve the comprehensive properties of composite materials for electronic packaging applications. For future studies, there are some key issues:

1) Future modeling efforts will focus on the interfacial shell layer to manipulate and understand the interaction between the fillers nanoparticles and the polymer matrix.

Based on the present discussed of the work reviewed here, it is clear that some polymers filled with high thermal conductivity fillers are well suitable for electronic applications for device encapsulation. However, significant advances are still needed to obtain thermally conductive composites sufficiently efficient to meet the requirements of most new market applications.

2) Decrease the loading of filler. As discussed above, the thermal conductivity of all composites greatly depend on the properties of fillers, they increase with the increase of the fillers loading. However, high inorganic filler loading also dramatically alters the mechanical behavior of composites, which is that industrial production is reluctant to face. So using less loading of filler for better performance of composites is needed.

3) Surface treatment of fillers is beneficial to increase the thermal conductivity and reduce dielectric constant of the composites, which is still a good method for preparing composites in future research.

Current commercial TIMs are capable of providing a thermal resistance between 0.03 and $0.1{ }^{\circ} \mathrm{C} \mathrm{cm}^{2} \mathrm{~W}^{-1}$ for fresh samples. ${ }^{152}$ However, due to degradation at large exposures to high temperatures as discussed earlier, the thermal performance can degrade severely depending on the operating temperature 
and time of exposure. There is no mechanistic understanding of these degradations and there is strong demand for fundamental physics based modeling that can relate the degradation of the polymer properties to thermal properties of the polymer composites. Use of nanoparticles and nanotubes is almost inevitable. However, any researchers in this area should benchmark thermal performance of their new concepts with the current commercially available TIMs. ${ }^{152-166}$ Research should also focus on minimizing the overall thermal resistance instead of just focusing on increasing thermal conductivity. This is because although $\lambda_{\text {TIM }}$ increases with increasing volume fraction, bulk thermal resistance reaches a minimum due to competing effects between the BLT and $\lambda_{T T M}$. A good physicsbased model for the contact resistance between the particle laden TIMs and the substrate is still lacking from the literatures. Contact resistance will become important for thin conducting TIMs. Modeling of the thermal resistance of vertically grown CNT array will be also needed in the future due to their promise as TIM.

There are many improvements and incremental changes on existing technologies, such as in the case of PLPs and continuous metal phase TIMs that will continue to deliver increasing performance to current application. In addition, technology on the verge of taking the leap towards industrial applications is actively being developed as in the case of CNT array TIMs, which could transform the TIM market in future.

\section{Acknowledgments}

The authors gratefully thank the National Natural Science Foundation of China (No.51707159), and Innovation Guidance Support Project for Taicang Top Research Institues (No. TC2019JC02). Authors also would like to thank the Analytical \& Testing Center of Northwestern Polytechnical University for their equipment supporting.

\section{Nomenclature}

A - Acceleration factor

$\mathrm{A}_{C}$ - Actual contact area

$\mathrm{A}_{n C}-$ Non-contact area occupied by air gaps

BLT - Bondline thickness

C - Empirical constant

DF - Density factor

$E_{a}-$ Activation energy

$G$ - Shear modulus

$G^{\prime}$ - Storage shear modulus

$G^{\prime \prime}$ - Loss shear modulus

$H$ - Hardness

$K$ - Consistency index

$\lambda_{c}-$ Thermal conductivity for composite

$\lambda_{m}$ - Thermal conductivity of the polymer matrix

$\lambda_{p}-$ Thermal conductivity of fillers $\lambda_{\text {TIM }}$ - Thermal conductivity of the TIM

$m$ - Mean asperity slope

$P$ - Pressure

$r$ - Radius of the substrate

$R_{b}$ - Thermal boundary resistance

$R_{c}$ - Contact resistance of TIM

$R_{\text {bulk }}$ - Bulk thermal resistance

$R_{c s}$ - Contact resistance between two bare solids

$R c_{T I M}$ - Contact resistance of an ideal TIM

$R_{j c}$ - Junction to case thermal resistance

$R_{T I M}$ - Thermal resistance of TIM (same as impedance)

$\psi_{c s}$ - Case to sink thermal resistance

$\psi_{J-a}-$ Junction to ambient thermal resistance

$\psi_{s a}$ - Sink to ambient thermal resistance

$\alpha$ - Biot number

$\sigma$ - Surface roughness

$\tau_{y}$ - Yield stress of the TIM

$\phi$ - Volume fraction of particles in TIMs

\section{References}

1. Z. Liu, Y. Chen, Y. Li, W. Dai, Q. Yan, F. Alam, S. Du, Z. Wang, K. Nishimura, N. Jiang, C. Lin and J. Yu, Nanoscale, 2019, 11,17600 - 17606.

2. F. Jiang, S. Cui, C. Rungnim, N. Song, L. Shi and P. Ding, Chem. Mater, 2019, 31, 7686 - 7695.

3. T. Na, S. Che, Y. Sun, X. Liu, J. Hao and C. Zhao, J. Appl. Poly. Sci., 2019, 136(7), 47078.

4. A. Islam, H. Lim, N. You, S. Ahn, M. Goh, J. Hahn, H. Yeo and S. Jang, ACS Macro Lett., 2018, 7, 1180 - 1185.

5. A. Alrashed, M. Gharibdousti, M. Goodarzi, L. Oliveira, M. Safaei and E. Filho,Int. J. Heat Mass Tran., 2018, 125, 920 - 932.

6. F. Wang, X. Zeng, Y. Yao, R. Sun, J. Xu and C. Wong, Sci. Rep-UK, 2016, 6, 19394

7. F. Zhang, Y. Feng, M. Qin, L. Gao, Z. Li, F. Zhao, Z. Zhang, F. Lv and W. Feng, Adv. Funct. Mater, 2019, 29, 1901383.

8. G. Yang, H. Yi, Y. Yao, C. Li and Z. Li, ACS Appl. Nano Mater, 2020.

9. J. Zhang, X. Wang, C. Yu, Q. Li, Z. Li, C. Li, H. Lu, Q. Zhang, J. Zhao, M. Hu and Y. Yao, Compos. Sci. Technol., 2017, 149, 41 - 47.

10. J. Hansson, T. Nilsson, L. Ye and J. Liu, Int. Mater. Rev., 2018, 63(1), 22 45.

11. J. S. Subramanian, P. Rodgers, J. Newson, T. Rude, Z. He, E. Besnoin, T. P. Weihs, V. Eveloy and M. Pecht, Mechanical and Multi-Physics Simulation and Experiments in Micro-Electronics and MicroSystemsEuroSimE, 2005, 681 - 686.

12. M. A. Lambert and L. S. Fletcher, J. Heat Tran., 2002, 124, 405 - 412.

13. R. Mahajan, C. P. Chiu and G. Chrysler, Proceedings of Institute of Electrical and Electronics Engineers, 2006, 94(8), 1476 - 1486.

14. A. Watwe and R. Prasher, Proceedings of 2001 ASME international mechanical engineering congress and exposition, 2001, 369, 123 - 128.

15. R. Mahajan, C. P. Chiu and R. Prasher, Electron Cooling, 2004, 10(1), 10.

16. R. S. Prasher, Proceedings of Institute of Electrical and Electronics Engineers, 2006, 98(8), 1571 - 1586.

17. R. S. Prasher, J. Heat Tran., 2001, 123(5), 969 - 975.

18. R. S. Prasher, P. Koning, J. Shipley and A. Devpura. J. Election Pack., 2003, 125(3), 386 - 391.

19. R. S. Prasher, J. Shipley, S. Prstic, P. Koning and J. Wang. J. Heat Tran., 2003, 125(6), 1170 - 1177.

20. R. S. Prasher, IEEE T. Compon. Pack. T., 2005, 28(2), 230 - 237. 
21. R. S. Prasher and J. C.Matayabus, IEEE T. Compon. Pack. T., 2004, 27(4), $702-709$.

22. R. S. Prasher, Proceedings of Institute of Electrical and Electronics Engineers, 2006, 94(8), 1571-1586.

23. C. P. Chiu and G. Solbrekken, International Symposium on Programming and Systems conference, 1999.

24. A. Sepehr and M. Sahimi, Phys. Rev. B, 1988, 38(10), 7173 - 7176.

25. A. V. Shenoy, Rheology of filled polymer system. Kluwer Academic, 1999, $1-390$.

26. T. L. Tansley and D. S. Maddison, J. Appl. Phys., 1991, 69(11), 7711 - 7713.

27. S. Narumanchi, M. Mihalic, K. Kelly and G. Eesley, 11th Intersociety Conference on Thermal and Thermomechanical Phenomena in Electronic Systems, 2008, 395 - 404.

28. R. Viswanath, M. Group and I. Corp, Thermal performance challenges from silicon to systems. Intel Technol J. Q3, 2000, 1-16.

29. D. Blazej, Thermal interface materials, 2003. Available from: http://www. electronics-cooling.com/2003/11/thermal-interface-materials/

30. X. C. Tong, Advanced maters for thermal management of electronic packaging. Springer, Vol. 30, 2011. Available from: http://link.springer.com/ 10.1007/978-1-4419-7759-5

31. L. Maguire, M. Behnia and G. Morrison, Microelectron. Reliab., 2005, 45 (3 - 4), 711 - 725 .

32. M. Ekpu, R. Bhatti and N. Ekere et al, Effects of thermal interface materials (solders) on thermal performance of a microelectronic package. Dtip, 2012 April.

33. J .Wilson, Thermal conductivity of solders, 2006. Available from: http:// www.electronics-cooling.com/2006/08/thermal-conductivity-of-solders/

34. J. A. Emerson, M. J. Rightley and J. A. Galloway et al, Minimizing the bondline thermal resistance in thermal interface materials without affecting reliability. Physics, 2005, 106 - 111.

35. R. S. Prasher and J. C. Matayabas, IEEE Transactions on Components Packaging Technology, 2004, 27(4), 702 - 709.

36. Gap Pad Products, 2016. Available from: http://www.bergquistcompany. com/thermal_materials/gap-pad.htm

37. De Sorgo M. Understanding phase change materials, 2002. Available from: http://www.electronics-cooling.com/2002/05/understanding-phase-changematerials

38. Thermally Conductive Adhesives, 2016. Available from: http://www. epoxies.com/products/thermallyconductive/

39. P. Bonnet, D. Sireude, B. Garnier and O. Chauvet, Appl. Phys. Lett., 2007, 91(20), 201910.

40. M. B. Jakubinek, M. A. White, M. Mu and K. I. Winey, Appl. Phys. Lett., 2010, 96, 94.

41. W. T. Hong and N. H. Tai, Diam. Relat. Mater, 2008, 17(7-10), 1577 - 1581.

42. J. Hong, J. Lee, C. K. Hong and S. E. Shim, Curr. Appl. Phys., 2010, 10(1), $359-363$.

43. G. Yujun, L. Zhongliang and Z. Guangmeng et al, Int. J. Heat Mass Tran., 2014, 74, 358 - 367.

44. B. M. Bozlar, D. He and J. Bai et al, Adv. Mater., 2010, 1654 - 1658.

45. J. Li, S. Qi and M. Zhang et al, J. Appl. Poly. Sci., 2015, 132(33), 42306.

46. K. Uetani, S. Ata and S. Tomonoh et al, Adv. Mater., 2014, 26 (33), 5857 $-5862$.

47. A. Yu, P. Ramesh and M. E. Itkis et al, J. Phys. Chem. C, 2007, 111(21), $7565-7569$.

48. M. Raza, A. V. K. Westwood and A. P. Brown et al, Journal of Electronic Materials: Materials Electron, 2012, 23(10), 1855 - 1863.

49. B. Debelak and K. Lafdi,Carbon, 2007, 45(9), 1727 - 1734.

50. K. M. F. Shahil and A. A. Balandin, Nano Lett., 2012, 12(2), 861 - 867.

51. B. Tang, G. Hu and H. Gao et al, Int. J. Heat Mass Tran., 2015, 85, 420 429.

52. Z. Lin, Y. Liu and S. Raghavan et al, ACS Appl. Mater. Int., 2013, 5(15),
$7633-7640$

53. S. Wang, Y. Cheng and R. Wang et al, ACS Appl. Mater. Inter., 2014, 6(9), 6481 - 6486.

54. K. Ahn, K. Kim and J. Kim, Ceram. Int., 2015, 41(8), 9488 - 9495.

55. Y. K. Shin, W. S. Lee and M. J. Yoo et al, Ceram. Int., 2013, 39(SUPPL.1), S569 - S573.

56. W. Y. Zhou, S. H. Qi and H. Z. Zhao et al, Polym. Polym. Compos., 2007, 28(2), 23 - 28.

57. C. Yuan, B. Duan and L. Li et al, ACS Appl. Mater. Inter., 2015, 7(23), $13000-13006$.

58. H. Yu, L. Li and T. Kido et al, J. Appl. Polym. Sci., 2011, $1763-1772$.

59. Z. Yuan, J. Yu and Z. He et al, FibersPolym., 2014, 15(12), 2581 - 2590.

60. K. Pashayi, H. R. Fard and F. Lai et al, J. Appl. Phys., 2012, 111(10), 104310.

61. J. Xu, A. Munari and E. Dalton et al, J. Appl. Phys., 2009, 106(12), 124310.

62. A. Munari, J. Xu and E. Dalton et al, 2009 59th Electronic Components and Technology Conference, 2009, 448 - 452.

63. N. Balachander, I. Seshadri and R. J. Mehta et al, Appl.Phys. Lett., 2013, 102(9), 093117.

64. S. H. Jeong, S. Chen and J. Huo et al, Sci. Rep-UK, 2015, 5, 18257.

65. S. W. Kim, H. S. Choi and K. S. Lee, Mater. Res. Bull., 2014, 60, 843 - 848.

66. M. A. Raza, A. V. K. Westwood and C. Stirling et al, Compos. Sci. Technol., 2015, 120,9 - 16 .

67. C. C. Teng, C. C. M. Ma and K. C. Chiou et al, Mater. Chem. Phys., 2011, 126(3), 722 - 728.

68. P. G. Ren, X. H. Si and Z. F. Sun et al, J. Polym. Res., 2016, 23(2), 21.

69. H. Im and J. Kim, Carbon, 2012, 50(15), 5429 - 5440.

70. Y. Hwang, M. Kim and J. Kim, Compos. Part A-Appl. S., 2013, 55, 195 202.

71. W. Yu, H. Xie and L. Yin et al, Int. J. Therm. Sci., 2015, 91, 76 - 82.

72. P. Bonnet, D. Sireude and B. Garnier et al, Appl. Phys. Lett., 2007, 91(20), 201910.

73. M. B. Jakubinek, M. A. White and M. Mu et al, Appl. Phys. Lett., 2010, 96, 94.

74. J. Hong, J. Lee and CK. Hong et al, Curr. Appl. Phys., 2010, 10(1), 359 363.

75. Z. Wang, Y. Fu and W. Meng et al, Nanoscale Res. Lett., 2014, 9(1), 643.

76. H. Ishida and S. Rimdusit, Thermochim. Acta, 1998, 320(1-2), 177 - 186.

77. K. M. Razeeb and E. Dalton, Nanowire polymer nanocomposites as thermal interface material. In: Boreddy R, editor. Advances in nanocomposites synthesis, characterization and industrial applications. Rijeka: InTech, 2011, Chapter Nanowire, 685 - 706.

78. K. Pashayi, H. R. Fard and F. Lai et al, Nanoscale, 2014, 6(8), 4292.

79. H. G. Lee and K. W. Paik, 2012 IEEE 62nd Electronic Components and Technology Conference, 2012, 2087 - 2090.

80. K. M. Razeeb and S. Roy, J. Appl. Phys., 2008, 103 (8), 084302.

81. V. Goyal and A. A. Balandin, Appl. Phys. Lett., 2012, 100(7), 073113.

82. L. Chen, Y. Y. Sun and J. Lin et al, Int. J. HeatMass Tran., 2015, 81, 457 -464 .

83. G. W. Lee, M. Park and J. Kim et al, Compos. Part A-Appl. S., 2006, 37 (5), $727-734$.

84. S. Y. Pak, H. M. Kim and S. Y. Kim et al, Carbon, 2012, 50(13), 4830 4838.

85. W. Yu, H. Xie and L. Yin et al, Int. J. Therm. Sci., 2015, 91, 76 - 82.

86. H. Chen, H. Wei and M. Chen et al, Appl. Surf. Sci., 2013, 283, 525 - 531.

87. B. Cola, T. S. Fisher and X. Xu, New York (NY): Nova Publishers, 2009.

88. E. Pop, D. Mann and Q. Wang et al, Nano Lett., 2006, 6(1), 96 - 100.

89. P. Kim, L. Shi and A. Majumdar et al, Phys. Rev. Lett., 2001, 87(21), 215502. 
90. A. M. Marconnet, M. A. Panzer and K. E. Goodson, Rev. Mod. Phys., 2013, 85(3), 1295 - 1326.

91. T. Tong, Y. Zhao and L. Delzeit et al, IEEE T. Compon. Pack. T., 2007, 30 (1), $92-100$.

92. B. A. Cola, J. Xu and T. S. Fisher, Int. J. HeatMass Tran., 2009, 52(15 - 16), $3490-3503$.

93. B. A. Cola, J. Xu and C. Cheng et al, J. Appl. Phys., 2007, 101(5), 1 - 9.

94. M. A. Panzer, G. Zhang and D. Mann et al, J. Heat Tran., 2008, 130 (5), 052401.

95. MA. Panzer, HM. Duong and J. Okawa et al, Nano Lett., 2010, 10(7), 2395 -2400 .

96. S. Kaur, N. Raravikar and B. A. Helms et al, Nat. Commun., 2014, 5, 1-8.

97. J. Xu and T. S. Fisher, Int. J. HeatMass Tran., 2006, 49(9-10), 1658-1666.

98. Q. Li, C. Liu and S. Fan, Nano Lett., 2009, 9, 3805-3809.

99. X. J. Hu, M. A. Panzer and K. E. Goodson, Journal of Heat Transfer Transfer ASME, 2007, 129(1), 91 - 93.

100. P. Kim, L. Shi, A. Majumdar and P. McEuen, Phys. Rev. Lett., 2001, 87(21), 215502.

101. J. Hone, M. C. Llaguno, M. J. Biercuk, A. T. Johnson, B. Batlogg, Z. Benes and J. E. Fisher, Appl. Phys. A, 2002, 74(3), 339-343.

102. M. J. Biercuk, M. C. Llaguno, M. Radosavljevic, J. K. Hyun, A.T. Johnson and J. E. Fischer, Appl. Phys. Lett., 2002,80(2),2767 - 2769.

103. E. T. Thostenson, Z. Ren and T. W. Chou, Compos. Sci. Technol., 2001, 61, $1899-1912$.

104. C. H. Liu, H. Huang, Y. Wu and S. S. Fan, Appl. Phys. Lett., 2004, 84(21), $4248-4250$.

105. C. W. Nan, G. Liu, Y. Lin and M. Li, Appl. Phys. Lett., 2004,85(16),3549 -3551 .

106. S. Huxtable, D. G. Cahill, S. Shenogin, L. Xue, R. OZisik, P. Barone, M. Usrey, M. S. Strano, G .Siddons,M. Shim and P. Keblinski, Nat. Mater., 2003, 2, $731-734$.

107. R. S. Prasher, Phys. Rev. B, 2008, 77, 075424.

108. X. Hu, L. Jiang and K. E. Goodson,9th Intersociety conferenceon thermal and thermomechanical phenomena in electronic system, 2004.

109. J. Xu and T. S. Fisher,The Ninth Intersociety Conference on Thermal and Thermomechanical Phenomena in Electronic Systems (IEEE Cat. No.04CH37543), 2004.

110. X. Hu, A. Padilla, J. Xu, T. S. Fisher and K. E. Goodson, J. Heat Tran.,2006, 128(11),1109 - 1113.

111. J. Xu and T. S. Fisher, 2004 international mechanical engineering congress and exposition, 2004, 60185.

112. T. Tong, Y. Zhao, L. Delzeit, A. Kashani, M. Meyyappan and A. Majumdar, IEEE T. Comp. Pack. T., 2007, 30(1), 92 - 100.

113. J. R. Wasniewski, D. H. Altman, S. L. Hodson, T. S. Fisher, A. Bulusu, S. Graham and B. A. Cola, J. Election Pack., 2012, 134, 020901.

114. M. T. Barako, Y. Gao, A. M. Marconnet, M. Asheghi and K. E. Goodson, 13th IEEE ITHERM conference, 2012, 1225 - 1232.

115. H. Wang, J. F. Feng, X. J. Hu and K. M. Ng, Chem. Eng. Sci., 2010, 65, $1101-1108$.

116. P. Zhang, Q. Li and Y. Xuan, Compos. Part A, 2014, 57, 1 - 7.

117. M. A. Peacock, C. K. Roy, M. C. Hamilton, R. W. Johnson, R. W. Knight and D. K. Harris, Int. J. HeatMass Tran., 2016, 97, 94 - 100.

118. M. T. Barako, Y. Gao, Y. Won, A. M. Marconnet, M. A. Asheghi and K. E. Goodson, IEEE T. Comp. Pack. Manuf., 2014, 4(12), 906 - 1913.

119. P. C. Irwin, Y. Cao, A. Bansal and L. S. Schadler, Annual report conference on electrical insulation anddielectric phenomena, 2003, 120 - 123.

120. L. Fan, B. Su, J. Qu and C. P. Wong, 9th international symposium on advanced packagingmaterials, 2004, 193 - 199.

121. S. A. Putnam, D. G. Cahill, B. J. Ash and L. S. Schadler, J. Appl. Phys., 2003, 94(10), 6785 - 6788.

122. B. Carlberg, T. Wang, Y. Fu, J. Liu and D. Shangguan, Electronic components and technology conference, 2008, 191 - 197.
123. C. Zanden, X. Luo, L. Ye and J. Liu, 19th internationalworkshop on thermal investigations of ICs and systems-therminic,2013, 286 - 292.

124. B. Carlberg, T. Wang, J. Liu and D. Shangguan, Microelectron. Int., 2009, 26(2), 28 - 36.

125. A. Yu, P. Ramesh, ME. Itkis, E. Bekyarova and RC. Haddon, J. Phys. Chem. Lett., 2007, 111, 7565 - 7569.

126. C. Lin and D. Chung, Carbon, 2009, 47, 295 - 305.

127. J. Xiang and L. T. Drzal, Sol. Energ. Mat. Sol. C., 2011, 965, 1811 - 1818.

128. M. Shtein, R. Nadiv, M. Buzaglo, K. Kahil and Oren Regev,Chem. Mater, 2015, 27, $2100-2106$.

129. K. M. F. Shahil and A. A. Balandin, Solid State Commun., 2012, 152, 1331 -1340 .

130. V. Goyal and A. A. Balandin, Appl. Phys. Lett., 2012, 100, 073113.

131. R. Aoki and C. P. Chiu. A testing apparatus for thermal interface materials. Proceedings of SPIE - The International Society for Optical Engineering, 1998, 3582, 1036 - 1041.

132. G. L. Solbrekken, C. P. Chiu, B. Byers and D. Reichebbacher, 7th Intersociety conferenceon thermal and thermomechanical phenomena in electronic systems, 2000, 48 - 54.

133. C. P. Chiu, G. L. Solbrekken and T. M. Young, 7 th Intersociety conference onthermal and thermomechanical phenomena in electronic systems, 2000, $52-62$.

134. C. Lin and D. Chung, Carbon, 2009, 47, $295-305$.

135. J. Xu, A. Munari, E. Dalton, A. Mathewson and K. M. Razeeb, J. Appl. Phys., 2009, 106, 124310.

136. R. Kempers, P. Kolodner, A. Lyons and A. J. Robinson, Rev. Sci.Instrum., 2009, 80, 095111.

137. C. Lin and D. Chung, J. Mater. Sci., 2007, 42, 9245 - 9255.

138. C. P. Chiu and G. Solbrekken, Characterization of thermal interface performance usingtransient thermal analysis technique.ISPS conference, 1999.

139. B. Smith, T. Brunschwiler and B. Michel, Microelectr. J., 2009, 40, 1379 $-1386$.

140. B. A. Cola, J. Xu, C. Cheng, X. Xu, T. S. Fisher and H. Hu, J.Appl. Phys., 2007, 101, 054313.

141. D. G. Cahill, Rev. Sci. Instrum., 2009, 61, $802-808$.

142. M. G. Burzo, P. E. Raad, P. L. Komarov, C. Wicaksono and T. Yoi, 29th IEEE SEMI-THERM symposium, 2013, 194 - 199.

143. A. J. McNamara, V. Sahu, Y. K. Joshi and Z. M. Zhang, ASME/JSME 8th thermal engineering joint conference, 2011.

144. B. Platek, T. Falat, P. Matkowski, J. Felba and A. Moscicki, Electronics systemintegration conference, 2014.

145. C. P. Chiu, G. L. Solbrekken, V. LeBonheur and Y. E. Xu, Proceedingsinternational symposium on advanced packaging materials processes, properties and interfacesCat. No. 00TH8507), International Microelectronics and Packaging Society, 2000, 265 - 270.

146. T. J. Goh, A. N. Amir, C. P. Chiu and J. Torresola, Proceedings of $3 \mathrm{rd}$ electronics packaging technology conference (EPTC 2000) (Cat. No. 00EX456), Institute of Electrical and ElectronicsEngineers, 2000, 65 - 71.

147. T. J. Goh, A. N. Amir, C. P. Chiu and J. Torresola, Proceedings of 51st electronic components and technologyconference, 2001, 1181 - 1186.

148. C. P. Chiu, B. Chandran, K. Mello and K. Kelley, Proceedings of 51st electroniccomponents and technology conference, 2001, 91 - 97.

149. G. K. Morris, M. P. Polakowski, L. Wei, M. D. Ball and M. G. Phillips, IWIPD, 2015, 111 - 114.

150. L. Bharatham, W. S. Fong, C. J. Leong and C. P. Chiu, Internationalconference on electronic materials and packaging,2006.

151. J. Due and A. J. Robinson, Appl. Therm. Eng., 2013, 50, 455 - 463.

152. E. Samson, S. Machiroutu, J. Y. Chang, I. Santos, J. Hermarding, A. Dani, R. Prasher, D. Song and D.Puffo,Some thermal technology and thermal management considerations in thedesign of next generation IntelR 
CentrinoTM mobile technology platforms. Intelligent Technology Journal, 2005, 9(1), 75 - 86.

153. Y. He, Rapid thermal conductivity measurement with a hot disk sensor: Part 1. Theoreticalconsiderations. Proceedings of the 30th North American thermal analysis society conference, 2002,4 99 - 504.

154. Standard test method for thermal transmission properties of thin thermally conductive solidelectrical insulation materials.American Society for Testing and Materials, D5470-93.

155. D. Zou, X. Huang, Y. Zhu, J. Chen and P. Jiang, Compos. Sci. Technol., 2019, 177, 88 - 95 .

156. X. Zhang, K. Wu, Y. Liu, B. Yu, Q. Zhang, F. Chen and Q. Fu, Compos. Sci. Technol., 2019, 175, 135 - 142.

157. S. Guo, R. Zheng, J. Jiang, J. Yu and C. Yan, Compos. Part B-Eng., 2019, 178,107489.

158. X. Hou, Y. Chen, L. Lyu, W. Dai, S. Zhao, Z. Wang, L. Fu, C. Lin, N. Jiang and J. Yu, ACS Appl. Nano Mater., 2019, 2, 360 - 368.

159. Y. Liu, M. Lu, K. Wu, S. Yao, X. Du, G. Chen, Q. Zhang, L. Liang and M.
Lu, Compos. Sci. Technol., 2019, 174, 1 - 10.

160. X. Shen, Z. Wang, Y. Wu, X. Liu and J. Kim, Carbon, 2016, 108,4 12 - 422.

161. H. Wang, K. Zhu, L. Yan, C. Wei, Y. Zhang, C. Gong, J. Guo, J. Zhang, D. Zhang and J. Zhang, Chem.Commun., 2019, 55, 5805 - 5808.

162. Y. Zhou, S. Wu and F. Liu, Mater. Lett., 2019, 237, 19 - 21.

163. Y. Zhou, S. Yu, H. Niu and F. Liu, Polymers-Basel, 2018, 10(12), 1412.

164. Y. Zhou, F. Liu and H. Wang, Polym. Composite., 2017, 38(4), 803 - 813.

165. J. Chen, X. Huang, Y. Zhu and P. Jiang, Adv. Funct. Mater, 2017, 27, 1604754 .

166. Y. Guo, K. Ruan, X.Yang, T. Ma, J. Kong, N. Wu, J. Zhang, J. Gu and Z. Guo, J. Mater. Chem. C, 2019, 7(23), 7035 - 7044.

Publisher's Note Engineered Science Publisher remains neutral with regard to jurisdictional claims in published maps and institutional affiliations. 